\begin{tabular}{c|c|c}
\hline \hline Vol. 248: 67-83, 2003 & MARINE ECOLOGY PROGRESS SERIES \\
Mar Ecol Prog Ser & Published February 20 \\
\hline
\end{tabular}

\title{
Effect of eelgrass Zostera marina canopies on flow and transport
}

\author{
Mohamed A. Abdelrhman* \\ US Environmental Protection Agency Office Research and Development, National Health and Environmental Effects \\ Research Laboratory, Atlantic Ecology Division, 27 Tarzwell Drive, Narragansett, Rhode Island 02882, USA
}

\begin{abstract}
Ecological effects of the interaction between submerged aquatic vegetation and currents depend on the plants and their associated organisms as well as the large-scale transport of dissolved and suspended constituents near the canopy. Mathematical models for airflow within plant canopies were adapted to describe water flow through and above meadows of aquatic eelgrass Zostera marina. The resulting model provided the vertical distribution of velocity and shear in a water column within the meadow, and it was developed to automatically conserve flow within the canopy. It was tested and calibrated with data from the laboratory and the field, and it performed adequately. The flow profile was nearly exponential within the canopy and logarithmic above it. The model was used to study how the eelgrass canopy affected the horizontal transport of conservative constituents. The most important finding was that the vertical distribution of a constituent determines whether the canopy will reduce or enhance its transport through the water column. This effect has direct implications for transport of nonconservative constituents such as dissolved oxygen, nutrients, organic carbon, and particulate pollen, larvae, plankton, and detritus. It also has direct implications for biological issues such as vertical distributions of photosynthesis and of recruitment of organisms on blades of grass while they are exposed to varying degrees of currents and shear.
\end{abstract}

KEY WORDS: Models $\cdot$ Eelgrass $\cdot$ Current profile $\cdot$ Transport

Resale or republication not permitted without written consent of the publisher

\section{INTRODUCTION}

Canopies of submerged aquatic vegetation (SAV) are intimately related to their nearby currents and ecology. They shelter finfish and shellfish, particularly as juveniles. They shelter the grazers of algae, and they thereby keep the water clear, which in turn increases the transmission of light and allows the SAV to grow. The plants compete with algae for nutrients. Their canopies provide resistance (Short \& Short 1984, Granata et al. 2001) that attenuates currents and helps suspended material and larvae settle into the canopy (Eckman et al. 1994, Gacia et al. 1999). The effect of seagrass canopies on sediment stability and detritus distribution controls the distribution of this habitat (Fonseca et al. 1982), and the enhanced sedimentation provides good ground for more species (including filter feeders, fishes, invertebrates, and plankton) to exist there (Granata et al. 2001). Intermeshed plants create dense barriers that deflect part of the flow upward and protect the sediment, larvae, and plant roots from being scoured (Fonseca et al. 1982). Nevertheless, under favorable hydrodynamic conditions and canopy height, flow may intensify near the bed and cause resuspension (Ward et al. 1984, Koch 1999).

Interactions between SAV and currents have been studied under natural conditions in the field (Koehl \& Alberte 1988, Worcester 1995, Sand-Jensen \& Mebus 1996, Koch 1996, Verduin \& Backhaus 2000, Granata et al. 2001) and in controlled laboratory settings (Anderson \& Charters 1982, Madsen \& Warncke 1983, Fonseca \& Fisher 1986, Koch 1994). The studies ranged from large-scale currents in and above canopies down to turbulence, drag, and boundary-layer structure near individual blades, and they were designed to relate canopy-flow interaction not only to the ecological relations noted above, but also to plant physiology. Freshwater canopies of Callitriche cophocarpa, Elodea cana- 
densis, Batrachium peltatum, and Sparganium emersum were shown to decrease flow rates with distance into the canopy from the top and the leading edge, and to increase flow rate and transport above the canopy (Sand-Jensen \& Mebus 1996). Velocities inside canopies were shown to create drag that affected breaking and detachment of blades; for eelgrass Zostera marina by Solana-Arellano et al. (1997) and for giant kelp Nereocystis luetkeana by Koehl \& Alberte (1988). The latter also showed that velocity directly affected self-shading, photosynthesis and fluxes of materials to the blade surface.

Increased currents affect the growth rate and distribution of the plants (Fonseca \& Kenworthy 1987). The enhanced shear on the blades reduces the diffusive boundary layer and helps inorganic carbon and nutrients flow to the plant, which increases photosynthesis (Koehl \& Alberte 1988, Koch 1996). Current patterns and speed control the pollination process (Ackerman 1986, Verduin et al. 1996). The attenuated flow within the canopy decreases pollen transport and the probability of interception by female carpels, which ultimately reduces plant productivity. Patchiness and erosion of grass canopies are strongly related to current strength and sediment loads (Fonseca et al. 1983). The strong currents and waves of storms may resuspend material within the canopy (Ward et al. 1984, Koch 1996), break or detach leaves and plants (Koehl \& Alberte 1988), or bury plants via high sedimentation (Fonseca et al. 1983).

Meadows of eelgrass Zostera marina are of special interest because they are sensitive bioindicators of water quality - they need fairly clear water and moderately low nutrients to survive. Consequently, eelgrass may be lost as agriculture and shoreline development increase the nitrogen in water and thereby increase the amount of phytoplankton to levels that limit the light reaching the grass (Dennison et al. 1993, Short \& Burdick 1996). In turn, eelgrass affects transport conditions in its vicinity by altering the exchange of water, which affects sedimentation, recycling of nutrients, and recruitment of fauna (Kenworthy et al. 1980, Rybicki et al. 1997). Eelgrass meadows may be regarded as net sinks of suspended matter in areas with low currents and as sources of detritus in areas with high currents (Fonseca et al. 1983, Koch 1999).

Understanding the transport of substances within eelgrass requires knowledge of how the plants affect the currents and visa versa. These relations have been studied in the field and the laboratory. In the field, Fonseca et al. (1983) studied how currents affect the structure of eelgrass meadows. They found that tidal currents directly affected the height and length of meadows, and they postulated that the meadows may be sources of detritus in high currents and sinks of sus- pended matter in low currents. This behavior may also affect the faunal assemblages within the meadows. Ackerman \& Okubo (1993) measured velocity in eelgrass meadows with electromagnetic current meters. Their data were the first to reveal the fundamental frequency of waving (monami) in the field. Grizzle et al. (1996) used similar meters to measure velocities in long ( 2 to $3 \mathrm{~m}$ ) eelgrass and characterized the waving and its effect on the dispersion patterns of Mytilus edulis on the blades. They emphasized the importance of this movement to underwater pollination. Worcester (1995) used dye to study advective transport and mixing due to slow currents in eelgrass beds with low density. He indicated that theses canopies reduced advection but did not affect turbulent mixing.

In the laboratory, Fonseca et al. (1982) studied the relation between current velocity, grass roughness, shear velocity, and the bending angle of blades with a recirculating saltwater flume. They indicated that the blades reached their maximum bending at currents of $\sim 50 \mathrm{~cm} \mathrm{~s}^{-1}$, a value that depended somewhat on plant density. Currents at the canopy surface were increased, and currents at the edge of the meadows dropped in unpredictable ways. Fonseca et al. indicated that the edge of the meadow was the most dynamic, where the high bending increased selfshading and the retarded currents increased the deposition of suspended particles. Fonseca \& Kenworthy (1987) indicated that high currents may help the leaves take up nutrients by reducing the diffusive boundary layer on the leaves and creating the scales of turbulence that bring nutrients to the leaves. These factors directly affect photosynthesis and primary production. Fonseca \& Kenworthy also emphasized the importance of currents and waves to distributing seedlings and detritus and affecting the structures of meadows. M. S. Fonseca \& M. A. R. Koehl (pers. comm.) studied the forces on blades from unidirectional and oscillatory currents and the interception of light by shoots arranged randomly and in rows. Ghisalberti \& Nepf (2002) used artificial eelgrass in a laboratory flume to study monamis and demonstrated the possibility that a mixing layer, not a boundary layer, formed at the top of the canopy. Nepf \& Vivoni (2000) described the flow and turbulence within eelgrass in a depth-limited environment, where pressure gradients cannot be ignored. They suggested that flow in the canopy can be divided into upper and lower zones dominated by vertical and horizontal mixing, respectively. Gambi et al. (1990) analyzed velocity and turbulence in flume flow with eelgrass by using an electromagnetic current meter. They indicated that the canopy enhanced turbulence at its upper boundary and increased the shear velocity above the canopy, and that velocity profiles above the canopy were logarithmic. 
None of these studies modeled the interaction between currents and SAV or eelgrass to generalize their observations. Modeling can be an inexpensive way of predicting some of the ecological implications under various scenarios of plant physiology, current, and sedimentation. Unfortunately, modeling flow in and above SAV lags far behind experiments describing the flow, and few models tackle this issue (Kutija \& Hong 1996, Schutten \& Davey 2000, Verduin \& Backhaus 2000). Schutten \& Davey (2000) used regression analysis of laboratory measurements to predict the hydraulic drag forces on various kinds of plants from a species-specific coefficient multiplied by the plant biomass times velocity to the 1.5 power. This method did not provide information about the flow within the canopy, however. Verduin \& Backhaus (2000) presented a 3-dimensional numerical model that described the interactions of SAV and flow for Amphibolis antarctica. It predicted the velocity profiles, kinetic energy, and drag forces in and above the canopy. It produced the same general trends as in field measurements but missed the observed minima in kinetic energy. Kutija \& Hong (1996) presented a steady-state, 1-dimensional numerical model for the vertical direction to study the additional resistance to flow provided by flexible reeds. The model was uncalibrated and unverified, and it did not include the interaction of plants with flow.

None of these models dealt with eelgrass. The model presented here attempts to fill the gap. It was developed independently and is much simpler. It was calibrated with laboratory data and verified with field data. It is also much less time-consuming and can be used by itself or as part of a module in larger numerical schemes.

\section{THE MODEL}

The model for eelgrass presented here is patterned after the more-extensive studies and models of airflow within and above terrestrial canopies. That research has generally shown that airflow is logarithmic and enhanced within the boundary layer above the canopy, and exponential and retarded within the canopy (Plate \& Quraishi 1964, Cionco 1965, 1983, Businger et al. 1971, Oliver 1971, Pruitt et al. 1973, Businger 1975, Hartog \& Shaw 1975, Legg \& Monteith 1975, Seginer et al. 1976, Raupach \& Thom 1981). I adapted these profiles to my model and defined the appropriate parameters for eelgrass canopies. A list of the important symbols used here is given in Table 1.

One major difference between terrestrial and aquatic vegetation is the way the fluid flows around them. Terrestrial vegetation can always have air flow above it (unconfined flow). Aquatic vegetation may have un- confined flow when in deep water or have confined flow when the water depth is less than twice the height of the canopy. Aquatic vegetation may even emerge from the water (Nepf \& Vivoni 2000). For stiff emergent marsh plants such as Spartina alterniflora, flow and turbulent energy decrease with distance from their leading edge, and sedimentation increases (Leonard \& Luther 1995). A model for describing drag, turbulence, and diffusion within emergent plants has been presented by Nepf (1999). Dye-injection experiments in the laboratory showed that dispersion was lower near emergent plants (Nepf et al. 1997a); a random-walk model has been used to predict turbulent diffusion within emergent marsh plants (Nepf et al. 1997b). The case of emergent plants does not apply to eelgrass, however, because its blades float on the surface when they are long enough to reach it. Although eelgrass may exist with confined or unconfined flow, its typical length of $1 \mathrm{~m}$ makes the unconfined case most common, except during slack low tide in relatively shallow environments. This work focuses on eelgrass in unconfined environments where the water is more than twice as deep as the canopy's height.

The analytical model offers empirical solutions for steady flow in and above dense eelgrass. Because the canopy is assumed to be wide and homogeneous, only its effects on vertical distributions of velocity and transport are presented here; lateral diversion around the canopy is assumed to be zero. The average height of the canopy is kept constant and roughly equal to the mean height of the blades (which are assumed erect). Although these assumptions, plus that of steady flow, are not always met in nature, they have also been used to develop analytical solutions for flow in terrestrial canopies (Businger 1975, Raupach \& Thom 1981, Raupach \& Shaw 1982, Raupach et al. 1996).

\section{Flow with no canopy}

Boundary-layer flow in areas without grass cover is usually described by a logarithmic profile (Sverdrup et al. 1942, Sternberg 1968):

$$
u_{z}=\frac{u_{*}}{\kappa} \log \left(\frac{z+z_{0}}{z_{0}}\right)
$$

where $u_{z}$ is the horizontal velocity at height $z_{1} u_{*}$ is a scaling factor for the velocity called the friction velocity $\left[u_{*}=\right.$ $\left(\tau_{\mathrm{b}} / \rho\right)^{1 / 2}$, where $\tau_{\mathrm{b}}$ is fluid shear stress at the bottom and $\rho$ is fluid density], $\kappa$ is von Karman's constant (0.4), and $z_{0}$ is the height of the bottom roughness elements. The roughness height defines the location of the datum $(z=0)$ for the vertical coordinate in Eq. (1) because the horizontal velocity becomes zero when $z$ equals zero. 
Table 1. List of important symbols used

\begin{tabular}{|c|c|}
\hline Quantity and dimension & Description \\
\hline$a\left(\mathrm{~cm}^{2}\right)$ & $\begin{array}{l}\text { Frontal area of blades per unit volume of } \\
\text { canopy }\end{array}$ \\
\hline$A\left(\mathrm{~cm}^{2}\right)$ & Horizontal area per blade \\
\hline C (dimensionless) & Coefficient of proportionality \\
\hline$c_{\mathrm{d}}$ (dimensionless) & Coefficient of drag \\
\hline$d(\mathrm{~cm})$ & Displacement height of velocity profile \\
\hline$h(\mathrm{~cm})$ & Height of canopy \\
\hline$H(\mathrm{~cm})$ & Total height of water column \\
\hline$K_{z}\left(\mathrm{~cm}^{2} \mathrm{~s}^{-1}\right)$ & $\begin{array}{l}\text { Vertical eddy viscosity coefficient within the } \\
\text { canopy }\end{array}$ \\
\hline$S\left(\mathrm{~cm}^{2}\right)$ & Projected area of blade facing flow \\
\hline$u_{h}\left(\mathrm{~cm} \mathrm{~s}^{-1}\right)$ & Free-stream velocity at the top of canopy \\
\hline$u_{z}\left(\mathrm{~cm} \mathrm{~s}^{-1}\right)$ & $\begin{array}{l}\text { Horizontal velocity at height } z \mathrm{~cm} \text { above a bed } \\
\text { without plants }\end{array}$ \\
\hline$U_{Z}\left(\mathrm{~cm} \mathrm{~s}^{-1}\right)$ & $\begin{array}{l}\text { Horizontal velocity at height } Z \mathrm{~cm} \text { above a bed } \\
\text { with plants }\end{array}$ \\
\hline$u_{*}\left(\mathrm{~cm} \mathrm{~s}^{-1}\right)$ & Friction velocity for a bed without plants \\
\hline$U *\left(\mathrm{~cm} \mathrm{~s}^{-1}\right)$ & Friction velocity for a bed with plants \\
\hline$w(\mathrm{~cm})$ & Blade width \\
\hline$z(\mathrm{~cm})$ & Height above a bed without plants \\
\hline$Z(\mathrm{~cm})$ & Height above a bed with plants \\
\hline$z_{0}(\mathrm{~cm})$ & $\begin{array}{l}\text { Height of roughness elements for a bed } \\
\text { without plants }\end{array}$ \\
\hline$Z_{0}(\mathrm{~cm})$ & $\begin{array}{l}\text { Height of roughness elements for a bed with } \\
\text { plants }\end{array}$ \\
\hline$\alpha$ (dimensionless) & $\begin{array}{l}\text { Attenuation coefficient for velocity within a } \\
\text { canopy }\end{array}$ \\
\hline$\rho\left(\mathrm{g} \mathrm{cm}^{-3}\right)$ & Density of water \\
\hline$\kappa($ dimensionless) & von Karman's constant $=0.4$ \\
\hline$\lambda(\mathrm{cm})$ & Mixing length of turbulence in canopy \\
\hline$\tau_{z}\left(\right.$ dyne $\left.\mathrm{cm}^{-2}\right)$ & Horizontal shear stress at height $z$ above bed \\
\hline
\end{tabular}

lyzed $d$ for different roughness elements (including crops, forests, and grass) and indicated that its value is $\sim 0.7$ times the height of the roughness element $h$. Businger (1975) used $d=0.67 h$, and Plate \& Quraishi (1964) assumed $d=h$. As the height of the grass decreases to zero, $d$ also reaches zero, and only bottom roughness causes drag on the fluid. Some researchers neglect the effect of $Z_{0}$ in the numerator of Eq. (2) relative to the effect of $d$ (e.g. Oliver 1971, Raupach \& Thom 1981, Grant et al. 1984). Plate \& Quraishi (1964) found that $Z_{0}=0.15 h$ for an artificial canopy. Businger (1975) presented relationships for $Z_{0}$ and $d$ and indicated that they depended on the spacing between plants, their height, and their shape:

$$
Z_{0}=0.5 h \frac{S}{A}
$$

where $h$ is the height of the plant, $S$ is its projected area facing the flow, $A$ is the horizontal area per element, and 0.5 is an empirical coefficient. This relationship is valid for sparse roughness elements, i.e. when $A \gg S$.

In order to consider a canopy of dense eelgrass, I modified Businger's analytical treatment. I substituted in Eq. (3) the dimensions of the upper part of the blades (above $d$ ) as the roughness elements. This part of the blade has a height of $h-d$ and a projected sur-

\section{Flow above the canopy}

Eelgrass beds alter the logarithmic profile of velocity (Fonseca et al. 1982, Fish and Wild Life Service 1984, Gambi et al. 1990). Businger (1975) assumed that the plants act as uniformly distributed roughness elements and showed that the velocity profile above their canopy can be expressed as:

$$
U_{z}=\frac{U_{*}}{\kappa} \log \left(\frac{Z-d+Z_{0}}{Z_{0}}\right)
$$

where $U_{Z}$ is the velocity at distance $Z$ above the bottom, $d$ is a displacement height due to the canopy, $U_{*}$ is the friction velocity for the canopy, and $Z_{0}$ is the roughness height of the canopy. Uppercase letters are used to differentiate similar terms between Eqs. (1) \& (2). Eq. (2) is the logarithmic velocity distribution analogous to Eq. (1) and indicates that the canopy exerts additional drag on the flow, as given by $d$. Jackson (1981) ana- face area of $(h-d) w$, where $w$ is the mean width of the blade. The equation then becomes:

$$
Z_{0}=0.5 \frac{(h-d)^{2} w}{A}
$$

I assumed that $d / h$ is a linear function of $S / A$ :

$$
\frac{d}{h}=c \frac{(h-d) w}{A}
$$

where $c$ is a coefficient of proportionality. From Eq. (5), $d$ is given by:

$$
d=\frac{c h^{2} w}{(A+c h w)}
$$

Substituting the expression for $d$ into Eq. (4) expresses the canopy's roughness height as:

$$
Z_{0}=\frac{0.5 w h^{2} A}{(A+c h w)^{2}}
$$

The coefficient $c$ depends on the number of blades, their width, and the height of the canopy $h$, and has to be cal- 


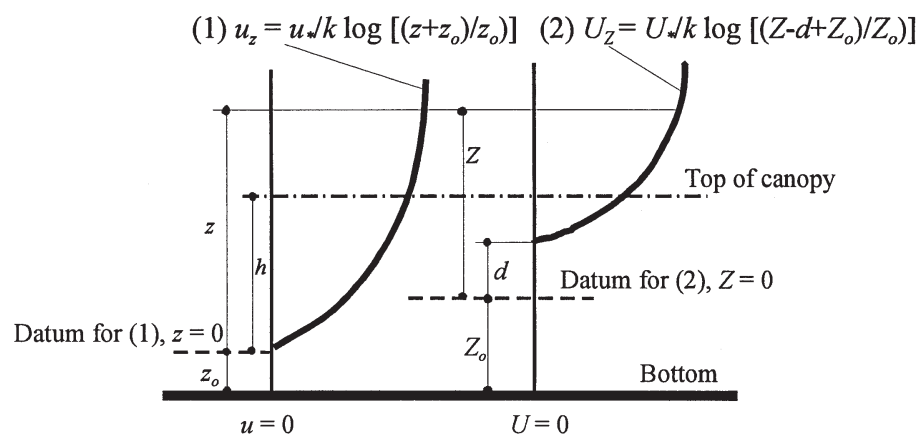

Fig. 1. Sketch of logarithmic velocity profiles without the displacement height (Eq. 1, left) and with it (Eq. 2, right). The zero velocity is at different locations above the bottom, $z_{0}$ for the former and $Z_{0}+d$ for the latter. The 2 equations do not share the same datum at $z=0$ and $Z=0$. The relation between $Z$ and $z$ is $Z=z+Z_{0}-Z_{0}$. Because $z_{0} \neq Z_{0}, U_{z}$ will be zero when $z=d+Z_{0}-Z_{0}$

ibrated with field data. Because $h$ depends on the speed of the current, $c$ and $Z_{0}$ will change accordingly.

Although Eqs. (1) \& (2) can be used independently, Eq. (2) must be modified in 2 important ways before it can be used with Eq. (1). The first change relates to $Z_{0}$, the second to $U_{*}$. The conservation of fluid mass from outside to inside the canopy dictates that the mathematical forms used in these 2 regions be consistent. As illustrated in Fig. 1, Eqs. (1) \& (2) do not share the same datum at $z=0$ and $Z=0$. At any height, $Z$ is equal to $Z$ $+z_{0}-Z_{0}$, which gives the following equation for flow above the canopy when substituted into Eq. (2):

$$
U_{z}=\frac{U_{*}}{\kappa} \log \left(\frac{z-d+z_{0}}{Z_{0}}\right)
$$

Eq. (8) shares the same datum with Eq. (1). However, because $z_{0} \neq Z_{0}, U_{z}$ will be zero when $z=d+Z_{0}-z_{0}$. The canopy friction velocity $\left(U_{*}\right)$ is calculated as described below.

\section{Flow through the canopy}

Flow within the canopy $(z \leq h)$ is referred to as 'canopy flow'. To deal with this flow in eelgrass beds, I adapted methods used for airflow within vegetation (see Appendix 1). The canopy flow is given by:

$$
u_{z}=u_{h} \exp \left[\alpha\left(\frac{z}{h}-1\right)\right]
$$

where $u_{h}$ is the free-stream velocity at the top of the canopy $(z=h)$ and $\alpha$ is an attenuation coefficient given by:

$$
\alpha=h\left[\frac{C_{\mathrm{d}} a}{2 \lambda^{2}}\right]^{\frac{1}{3}}
$$

where $C_{\mathrm{d}}$ is a velocity-dependent drag coefficient, $a$ is the frontal area of individual elements per unit volume of canopy (Raupach $\&$ Thom 1981), and $\lambda$ is the mixing length of the turbulent flow within the canopy, assumed constant (Cionco 1965). For a uniform canopy of eelgrass, $a$ is a constant equal to $w / A$, and $C_{\mathrm{d}}$ relates to the drag on a single blade. Wright \& Brown (1967) postulated that $c_{\mathrm{d}}$ is independent of height when the roughness elements are uniform with height and independent of velocity when the turbulence field is fully developed. Thus, $c_{\mathrm{d}}$ can be treated as a constant. The attenuation coefficient ( $\alpha$ ) usually falls between 2 and 3 (Wright \& Brown 1967, Raupach \& Thom 1981). Many investigators (including Businger 1975, Hartog \& Shaw 1975, Legg \& Monteith 1975, Niklas 1992) have used Eq. (9) to represent flow in terrestrial canopies. Although this equation satisfies the boundary condition at the top of the canopy, it does not at the bottom $\left(u_{0} \neq 0\right.$ at $\left.z=0\right)$, but the difference is small and is usually neglected in terrestrial systems. For flow within eelgrass, I assumed that the water depth exceeds the height of the canopy (as in unconfined air flow for terrestrial systems) and used the same equation.

\section{The friction velocity for the canopy}

I calculated $U_{*}$ from conservation of fluid mass between the water column before the canopy, where Eq. (1) applies, and the column within the canopy, where Eqs. (8) \& (9) hold:

$$
\begin{aligned}
& \int_{0}^{H} \frac{u_{*}}{\kappa} \log \left(\frac{z+z_{0}}{z_{0}}\right) d z= \\
& \int_{0}^{h} u_{h} \exp \left[\alpha\left(\frac{z}{h}-1\right)\right] d z+\int_{h}^{H} \frac{U *}{\kappa} \log \left(\frac{z-d+z_{0}}{Z_{0}}\right) d z
\end{aligned}
$$

Here $H$ is the total depth of the water column. Eq. (8) explicitly assumes that the logarithmic layer extends to the water surface. This is a reasonable assumption in the shallow environments where eelgrass exists $(<5 \mathrm{~m})$. Substituting $u_{h}$ from Eq. (8) and integrating gives the relationship between $U_{*}$ and $u_{*}$ as:

$$
\begin{aligned}
& U_{.}=u \cdot\left[\left(H+z_{0}\right) \log \left(\frac{H+z_{0}}{z_{0}}\right)-H\right] / \\
& \left\{\frac{h}{\alpha} \log \left(\frac{h-d+z_{0}}{Z_{0}}\right)\left[1-\mathrm{e}^{-\alpha}\right]+\left(H-d+z_{0}\right) \log \left(\frac{H-d+z_{0}}{Z_{0}}\right)\right. \\
& \left.-\left(h-d+z_{0}\right) \log \left(\frac{h-d+z_{0}}{Z_{0}}\right)-(H-h)\right\}
\end{aligned}
$$

\section{CALIBRATION}

I tested, calibrated, and verified the model with laboratory data from Gambi et al. (1990), who measured velocity and turbulence within and above eelgrass 
Table 2. Phenological parameters from a random sample of 20 shoots of eelgrass used in laboratory flume experiments (Gambi et al. 1990)

\begin{tabular}{|c|c|c|}
\hline Parameter & Mean & $\mathrm{SD}$ \\
\hline Sheath length $(\mathrm{cm})$ & 3.68 & 0.47 \\
\hline Blade length $(\mathrm{cm})$ & 7.9 & 3.5 \\
\hline Blade width $(\mathrm{cm})$ & 0.28 & 0.04 \\
\hline Canopy height (cm) & 11.44 & 2.47 \\
\hline Blades shoot ${ }^{-1}$ & 3.9 & 0.76 \\
\hline Blade area shoot ${ }^{-1}\left(\mathrm{~cm}^{2}\right)$ & 9.06 & 3.4 \\
\hline
\end{tabular}

canopies. The phenological parameters of their plants are summarized in Table 2 . They used beds with densities of $400,600,800,1000$, and 1200 shoots $\mathrm{m}^{-2}$ and free-stream velocities of 5,10 , and $20 \mathrm{~cm} \mathrm{~s}^{-1}$. In addition to measuring the velocity profile at a control section $25 \mathrm{~cm}$ upstream from the leading edge of the grass bed, they measured profiles at 25,50, 75, and $100 \mathrm{~cm}$ downstream from the leading edge, and at $2 \mathrm{~cm}$ vertical increments through the $20 \mathrm{~cm}$ water column.

I tested and calibrated the models on the intermediate profiles (50 and $75 \mathrm{~cm}$ ) and fine-tuned the results with the profile at $100 \mathrm{~cm}$. I readjusted the velocity profiles measured at 50 and $75 \mathrm{~cm}$ to include flow that was diverted laterally around the canopy. The fraction of flow so diverted was calculated for each downstream location by using the difference between the integrated flow at the control section and at the downstream location. The velocity measured at each height was then increased by the fraction of the flow diverted laterally. This adjustment restored the conservation of mass between the control profile and the intermediate profiles.

I calibrated the model for 1000 shoots $\mathrm{m}^{-2}$ and at free-stream velocities of 5 , 10 , and $20 \mathrm{~cm} \mathrm{~s}^{-1}$. The values of the parameters used for calibrating at each of the velocities are listed in Table 3 . The shoot density gave a blade density of $3900 \mathrm{~m}^{-2}$ because an average shoot has $3.9 \pm 0.76$ blades (Table 2). That allowed the horizontal area per blade (A) to be calculated at $2.56 \mathrm{~cm}^{2}$. The mixing length $(\lambda)$ has been indicated by laboratory and field observations on terrestrial and aquatic canopies to be of the order of the canopy's height (Raupach et al. 1996, Ghisalberti \& Nepf 2002). I assumed that it could be reasonably estimated as equal to the displacement height $(d)$ which was calculated from
Eq. (6). The coefficient $c_{\mathrm{d}}$ was estimated with data from M. S. Fonseca \& M. A. R. Koehl (pers. comm.), who measured the lateral forces on individual shoots (average of 4.82 blades shoot ${ }^{-1}$ ) arranged randomly or in rows. They indicated that these forces were independent of position in the meadow. Randomly distributed shoots showed slightly higher drag than shoots arranged in rows, however. I calculated the drag coefficient from the balance of measured forces and fluid drag on a single blade (Eq. A3) for blades $21 \mathrm{~cm}$ long and $0.3 \mathrm{~cm}$ wide in water with a density of $1.023 \mathrm{~g} \mathrm{~cm}^{-3}$ (temperature $25^{\circ} \mathrm{C}$, salinity $35 \mathrm{ppt}$ ) and obtained a mean value of 0.2 . A different analysis of blades $45 \mathrm{~cm}$ long and $0.58 \mathrm{~cm}$ wide (Abdelrhman unpubl.) calculated the drag coefficient from the balance of horizontal forces and obtained 0.7. Although the drag coefficient depends on the size of the plant, its age, its epiphytic growth (if any), and properties of the water that directly affect its density and viscosity (temperature and salinity), I used the constant 0.7 to test the performance of the model against velocity profiles at 50 and $75 \mathrm{~cm}$ from the leading edge. The results are shown in Fig. 2. First, a logarithmic velocity profile (Eq. 1) was

Table 3. Model parameters calculated from laboratory data of Gambi et al. (1990) for a plant density of 1000 shoots $\mathrm{m}^{-2}$ (3900 blades $\left.\mathrm{m}^{-2}\right)$ at free-stream velocities of 5,10 , and $20 \mathrm{~cm} \mathrm{~s}^{-1}$

\begin{tabular}{|c|c|c|c|c|}
\hline Parameter & & Value & & Source \\
\hline $\begin{array}{l}\text { Free-stream velocity } \\
\left(\mathrm{cm} \mathrm{s}^{-1}\right)\end{array}$ & 5 & 10 & 20 & $\begin{array}{l}\text { Reproduced from the } \\
\text { figures of Gambi et al. (1990) }\end{array}$ \\
\hline $\begin{array}{l}\text { Horizontal area per } \\
\text { blade, } A\left(\mathrm{~cm}^{2}\right)\end{array}$ & 2.56 & 2.56 & 2.56 & $\begin{array}{l}\text { Calculated from the density } \\
\text { of blades ( } 3900 \text { blades } \mathrm{m}^{-2} \text { ) }\end{array}$ \\
\hline Width of blade, $w(\mathrm{~cm})$ & 0.3 & 0.3 & 0.3 & Table 2 \\
\hline Water depth, $H(\mathrm{~cm})$ & 20 & 20 & 20 & Gambi et al. (1990) \\
\hline Canopy height, $h(\mathrm{~cm})$ & 10.50 & 9.32 & 9.00 & $\begin{array}{l}\text { Measured from the figures } \\
\text { of Gambi et al. (1990) }\end{array}$ \\
\hline $\begin{array}{l}\text { Friction velocity outside } \\
\text { canopy, } u_{*}\left(\mathrm{~cm} \mathrm{~s}^{-1}\right)\end{array}$ & 0.38 & 0.58 & 1.05 & $\begin{array}{l}\text { Calibrated from free-stream } \\
\text { profiles }\end{array}$ \\
\hline $\begin{array}{l}\text { Friction velocity within } \\
\text { canopy, } U_{*}\left(\mathrm{~cm} \mathrm{~s}^{-1}\right)\end{array}$ & 2.8 & 4.57 & 7.74 & Calculated from Eq. (12) \\
\hline $\begin{array}{l}\text { Proportionality } \\
\text { coefficient, } c\end{array}$ & 0.2 & 0.2 & 0.2 & $\begin{array}{l}\text { Calibrated using overlying } \\
\text { profile, Eq. (8) }\end{array}$ \\
\hline $\begin{array}{l}\text { Canopy drag } \\
\text { coefficient, } c_{\mathrm{d}}\end{array}$ & 0.7 & 0.7 & 0.7 & $\begin{array}{l}\text { Calibrated using canopy } \\
\text { profile, Eq. (9) }\end{array}$ \\
\hline $\begin{array}{l}\text { Roughness height be- } \\
\text { fore canopy, } z_{0}(\mathrm{~cm})\end{array}$ & 0.0106 & 0.0024 & 0.0025 & $\begin{array}{l}\text { Calibrated from free-stream } \\
\text { profiles, Eq. (1) }\end{array}$ \\
\hline $\begin{array}{l}\text { Roughness height with- } \\
\text { in canopy, } Z_{0}(\mathrm{~cm})\end{array}$ & 4.16 & 3.42 & 3.23 & Calculated from Eq. (7) \\
\hline $\begin{array}{l}\text { Displacement height, } \\
d(\mathrm{~cm})\end{array}$ & 2.07 & 1.67 & 1.57 & Calculated from Eq. (6) \\
\hline Mixing length, $\lambda(\mathrm{cm})$ & 2.07 & 1.67 & 1.57 & $\begin{array}{l}\text { Set equal to displacement } \\
\text { height } d\end{array}$ \\
\hline
\end{tabular}


fitted to data from the control profile $(25 \mathrm{~cm}$ upstream of the canopy), and then $u_{*}$ and $z_{0}$ were calculated (Table 3). The calculated values of $u_{*}$ were very close to those presented by Gambi et al. (1990). Various values of $c$ were tried, as described below.

The main calibration of the model was in adjusting the coefficient $c$ to minimize the least-squares error between the modeled and observed velocities at $1 \mathrm{~cm}$ increments of height from the bottom to the water surface. Velocity profiles for 5,10 , and $20 \mathrm{~cm} \mathrm{~s}^{-1}$ and plant densities of $1200,1000,800,600$, and 400 shoots $\mathrm{m}^{-2}$ $\left(1560,2340,3120,3900\right.$, and 4680 blades $\mathrm{m}^{-2}$, respectively) were used. Currents observed $100 \mathrm{~cm}$ downstream of the leading edge of the canopy were used (Gambi et al. 1990). For ease in comparing model and data, all profiles were normalized to the measured velocity at the surface. An example of the measured and modeled profiles is shown in Fig. 3. Similar agree-
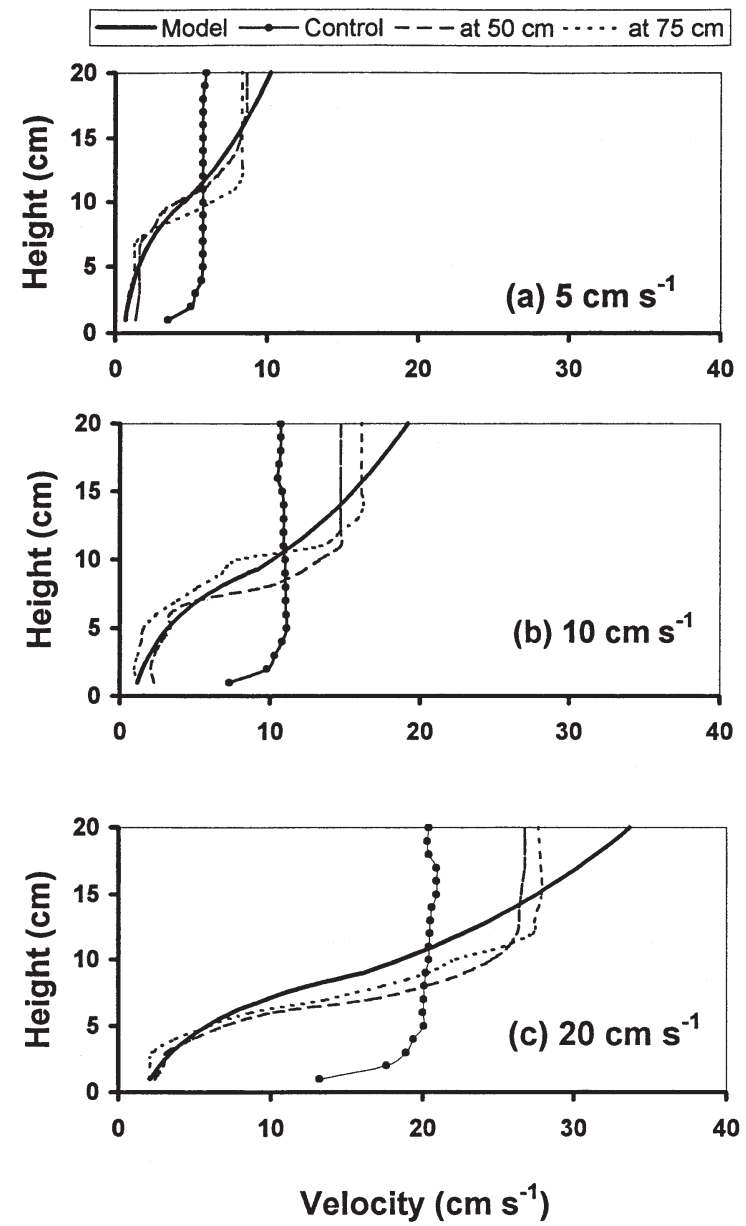

Fig. 2. Comparisons of velocity profiles from the calibrated model and measurements (from Gambi et al. 1990) at 50 and $75 \mathrm{~cm}$ downstream from the leading edge of a canopy with plant density of 1000 shoots $\mathrm{m}^{-2}\left(3900\right.$ blades $\left.\mathrm{m}^{-2}\right)$ at velocities of (a) 5, (b) 10, and (c) $20 \mathrm{~cm} \mathrm{~s}^{-1}$ ment was found between model and observations for all plant densities and velocities. The model performed best with higher densities of blades. The value of $c$ for the various speeds and plant densities is shown in Fig. 4. (This coefficient may need to be re-evaluated with other plant morphologies and flows.) The best-fit coefficients used in the model, as well as values for other parameters, are presented in Table 3 . The calibration produced reasonable distributions of velocity within and above the beds. The only noticeable deviation was near the surface, where the profile was calculated to be logarithmic but the data were uniform. This deviation can be rectified when the depth of the uniform flow is known or can be inferred. The model was then considered to be satisfactorily calibrated and tested, and was then applied to field data.

\section{APPLICATION OF THE MODEL TO FIELD DATA}

The field data were collected within eelgrass canopies near Rose Island, East Passage of Narragansett Bay, Rhode Island, on 23 September 1999. They represent rough reconnaissance information taken before this modeling study and were not

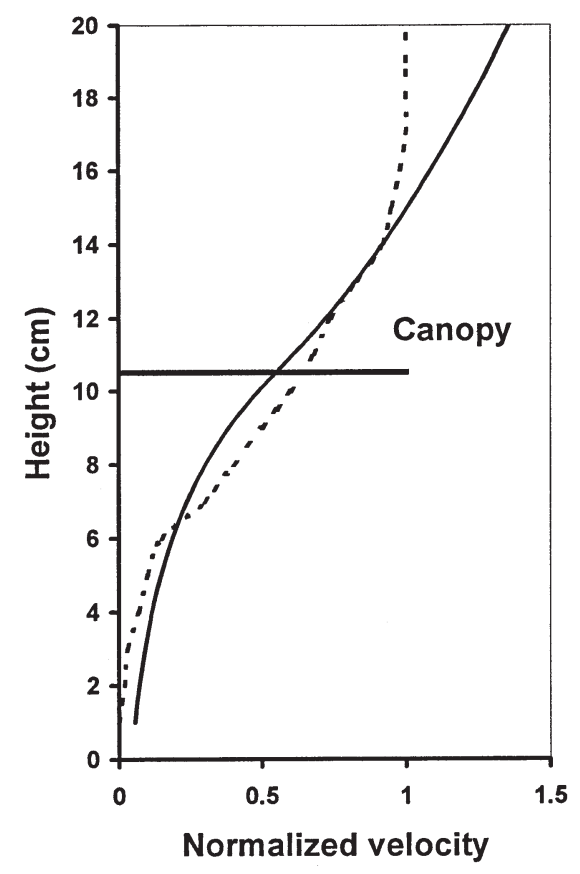

Fig. 3. Comparisons of velocity profiles from the calibrated model (solid line) and measurements $100 \mathrm{~cm}$ downstream from the leading edge of canopy (dashed line) for plant density of 1200 shoots $\mathrm{m}^{-2}$ (4680 blades $\mathrm{m}^{-2}$ ) and a velocity of $5 \mathrm{~cm} \mathrm{~s}^{-1}$. Both profiles were normalized to the measured velocity at the surface 


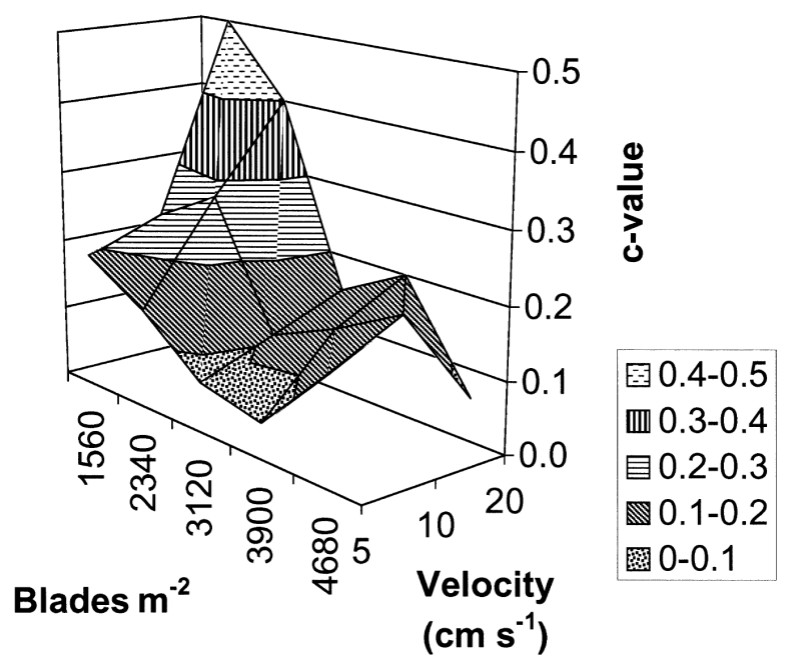

Fig. 4. Calibration for the proportionality coefficient $C$ (Eq. 5) using plant densities of 400,600,800,1000, and 1200 shoots $\mathrm{m}^{-2}\left(1560,2340,3120,3900\right.$, and 4680 blades $\mathrm{m}^{-2}$, respectively) and velocities of 5,10 , and $20 \mathrm{~cm} \mathrm{~s}^{-1} . c$ declines to a value of $\sim 0.2$ for plant densities of $\geq 800$ shoots $\mathrm{m}^{-2}(\geq 3000$ to 3500 blades $\mathrm{m}^{-2}$ ) and velocities of $\leq 20 \mathrm{~cm} \mathrm{~s}^{-1}$. The overall

average $c$ for the tested velocities and densities was 0.19

designed for it. They were used to roughly validate the model only because no other data were available. Depths and velocities were measured at 2 stations with an acoustic transducer (DT4000; BioSonics 1998) and current meter (Marsh McBirny Model-2000) (Fig. 5). The acoustic transducer provided information about the height of the canopy and the water depth (e.g. Sabol et al. 1997, 2002). The current meter was attached to a graded stainless-steel rod and positioned to measure velocities from the bottom to $50 \mathrm{~cm}$ below the surface at $10 \mathrm{~cm}$ increments every half hour. It was visually and manually aligned to face the direction of maximum speed at each depth.

Twelve velocity profiles were measured in all. Velocities near the slack period were so weak $\left(<5 \mathrm{~cm} \mathrm{~s}^{-1}\right)$ that they had indistinct directions and profiles. Although velocities were not measured outside the canopy, the measurements inside it were used with logarithmic profiles for the various tidal phases (Eq. 1) to calculate friction velocities. First, the value of $z_{0}$ had to be obtained. The value of $z_{0}$ was taken to be $0.2 \mathrm{~cm}$, a value typical for sandy beds (Bilhco \& Partheniades 1971), because 3 sediment cores at each site indicated that they were 92 to $95 \%$ sand. The value of $u_{*}$ was then calculated by assuming that mass was conserved between the measured velocity profiles and the logarithmic profile (Eq. 1). Integrating the measured velocities of each profile and equating the calculated flow to the logarithmic flow allowed the friction velocity to be defined as:

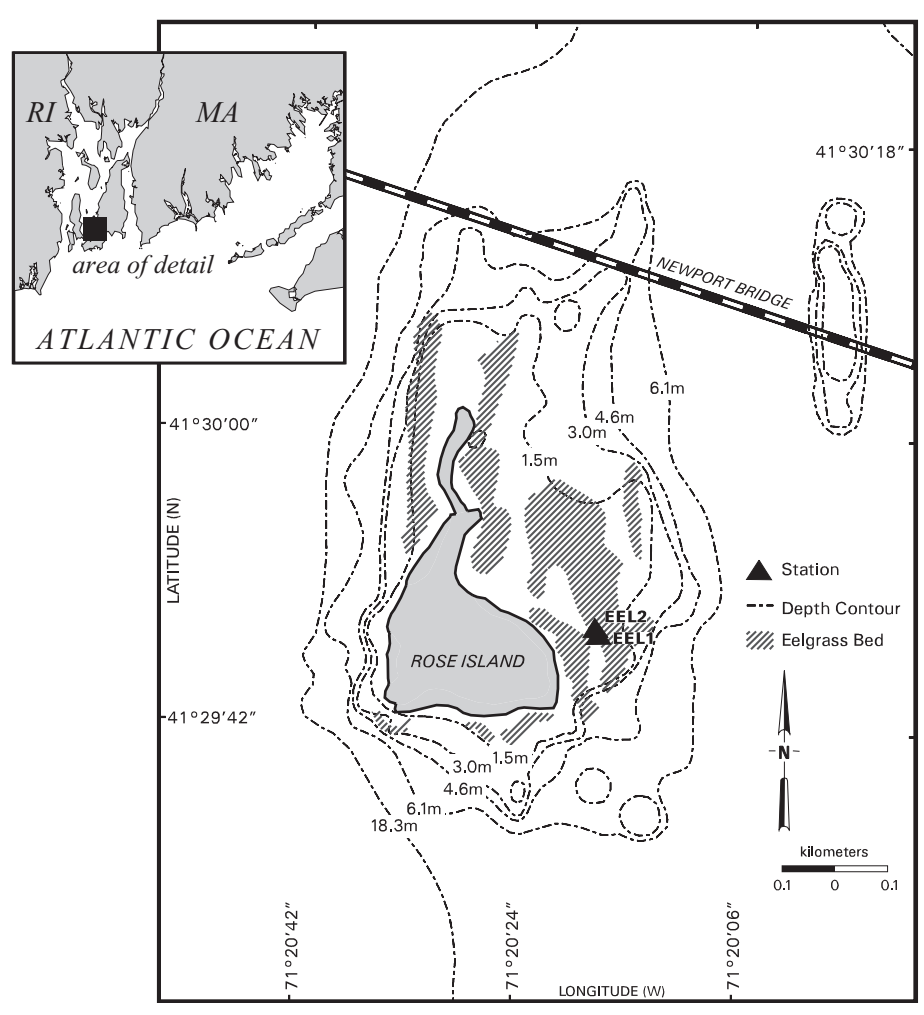

Fig. 5. Location of eelgrass Stns EEL1 and EEL2 near Rose Island, East Passage of Narragansett Bay, Rhode Island. The data for Stn EEL1 extended from 10:30 to 12:30 h EST, during the ebbing tide between MWL and LWL; for Stn EEL2, from 13:10 to 15:50 h EST, during the flooding tide between LWL and MWL

$$
u .=\frac{I \kappa}{\left[\left(H+z_{0}\right) \log \left(\frac{H+z_{0}}{z_{0}}\right)-H\right]}
$$

where $I$ is the integrated value of the measured profile. The water depth $(H)$ and the friction velocity $\left(u_{*}\right)$ change with tide (see 'Discussion'). The von Karman coefficient and $z_{0}$ were assumed to be constant. Table 4 presents the calculated values of $u_{*}$ for the measured profiles at the 2 stations, as well as other model parameters. The average height of the canopy (h) was obtained from the backscattered acoustic signal. The water depth was obtained manually from the graded rod and confirmed with the acoustic signal.

The density and morphology of the plants were estimated from representative samples collected by divers from quadrats of $25 \mathrm{~cm}$ by $25 \mathrm{~cm}$. Four replicates were collected at Stn EEL1, 3 at Stn EEL2. The number of shoots and the number of blades per shoot were calculated for each quadrat. The maximum length of the blades was $63 \mathrm{~cm}$, and sheath lengths varied from 5 to $22 \mathrm{~cm}$. The blade density was 
$1750 \mathrm{~m}^{-2}$ at Stn EEL1 and $1600 \mathrm{~m}^{-2}$ at Stn EEL2, with blade widths of 0.414 and $0.434 \mathrm{~cm}$, respectively. The drag coefficient was set to 0.7 , as noted above. I found that $c=1.2$ made the model best resemble the field observations, which I attributed to a difference in plant morphology.

Results from the model (Fig. 6) indicate that it reasonably estimated the flow in and above grass canopies without further tuning. It performed best with slow currents $\left(\sim 10 \mathrm{~cm} \mathrm{~s}^{-1}\right)$. Some discrepancies existed with higher currents (not shown); they were attributed to bending of the blades and a consequent reduction in the height and drag of the canopy, which are not considered by this model. Given the uncertainties and high variability in the measured velocities, the model provided reasonable first estimates of flow within grass canopies.

\section{EFFECT OF CANOPY ON TRANSPORT}

I assessed how a hypothetical canopy (density $=1750$ blades $\mathrm{m}^{-2}, h=70 \mathrm{~cm}, w=0.4 \mathrm{~cm}$ ) affected the transport of a conservative constituent flowing across it. The water depth $(H)$ was assumed to be $200 \mathrm{~cm}$, with $u_{*}$ being $1.63 \mathrm{~cm} \mathrm{~s}^{-1}$ and $z_{0}$ being $0.1 \mathrm{~cm}$. The coefficients $C_{\mathrm{d}}$ and $C$ were set at 0.7 and 1.2 , respectively. Fig. 7 shows the logarithmic profile (Eq. 1) and the profile from the analytical model (Eqs. 8 \& 9).

I used a conservative constituent with 3 linear vertical distributions: uniform, upper triangle, and lower triangle, that have the same integrated mass (Fig. 8), i.e.

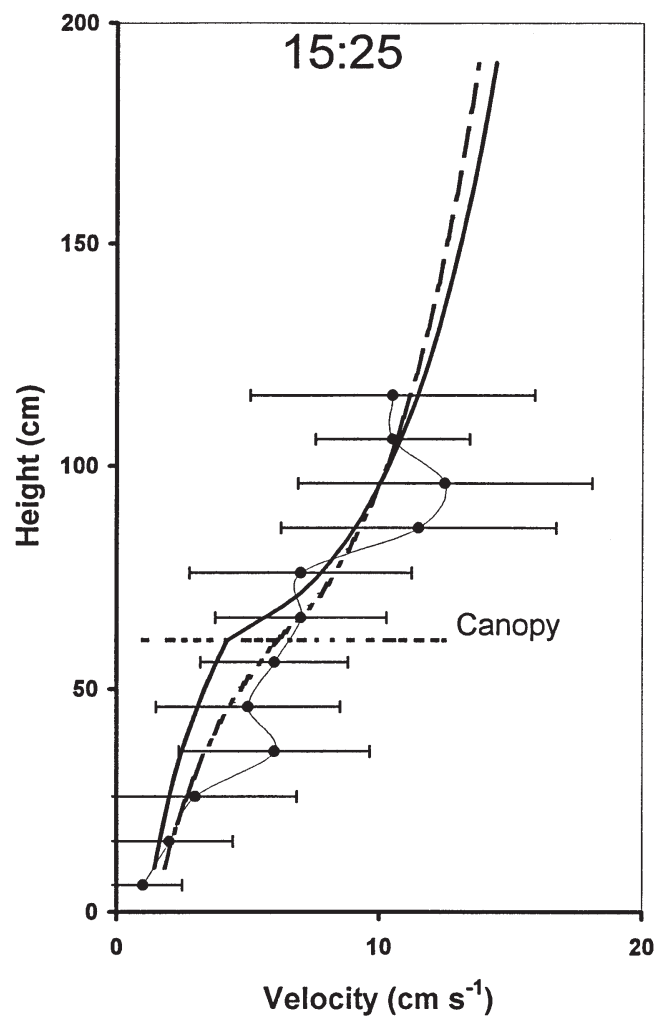

Fig. 6. Comparison of predicted velocity profiles (solid line) and field observations (dots with error bars) at 15:25 h EST on 23 September 1999. Observed slack low tide was at 13:00 $\mathrm{h}$ EST. Results using the suggested empirical value of $d=0.7 \mathrm{~h}$ are shown by dashed line. To calculate the error bars, each velocity profile was first normalized by its depth-averaged value $\left(u_{\text {average }}\right)$ then the standard deviation $\left(\sigma_{z}\right)$ of all the normalized velocities was calculated for each depth $(z)$ and the error bars were chosen to be $\pm 2 \sigma_{z} u_{\text {average }}$
Table 4. Model parameters calculated from velocity profiles near Rose Island (Fig. 5) at different times during ebbing tide (Stn EEL1) and flooding tide (Stn EEL2). Observed slack low tide was at 13:00 h EST. Depth was measured with a graded rod and acoustic transducer (in parentheses), which also measured the height of the canopy. The friction velocity was calculated from Eq. (13)

\begin{tabular}{|lcccc|}
\hline Stn & Time EST & $\begin{array}{c}\text { Depth, } H \\
(\mathrm{~cm})\end{array}$ & $\begin{array}{c}\text { Friction } \\
\text { velocity, } u_{*} \\
\left(\mathrm{~cm} \mathrm{~s}^{-1}\right)\end{array}$ & $\begin{array}{c}\text { Canopy } \\
\text { height, } h \\
(\mathrm{~cm})\end{array}$ \\
\hline EEL1 & $10: 30$ & $225(218)$ & 1.63 & 62 \\
& $10: 50$ & $210(221)$ & 1.67 & 57 \\
& $11: 20$ & $210(216)$ & 1.38 & 64 \\
& $11: 45$ & $200(205)$ & 0.88 & 62 \\
& $12: 05$ & $200(187)$ & 0.70 & 53 \\
EEL2 & $12: 30$ & $200(184)$ & 0.24 & 63 \\
& $13: 10$ & $200(185)$ & 0.00 & 61 \\
& $13: 55$ & $200(196)$ & 0.25 & 62 \\
& $14: 20$ & $210(194)$ & 0.50 & 64 \\
& $15: 00$ & $225(218)$ & 0.26 & 62 \\
& $15: 25$ & $235(219)$ & 0.61 & 68 \\
\hline
\end{tabular}

$$
\begin{gathered}
C(z)_{\text {unif }}=1 \\
C(z)_{u p \nabla}=\left(\frac{2}{H}\right) z \\
C(z)_{\text {low }}=\left(\frac{2}{H}\right)(H-z)
\end{gathered}
$$

where $c(z)$ is the concentration $\left(\mu \mathrm{g} \mathrm{cm}^{-3}\right)$ at height $z(\mathrm{~cm})$. These 3 distributions are simplifications of ecologically important profiles. For example, the uniform distribution can represent dissolved constituents (e.g. nutrients), fine particles, and colloids (diameter $<63 \mu \mathrm{m})$; the distribution with a maximum at the surface may represent phytoplankton, dissolved oxygen, and 


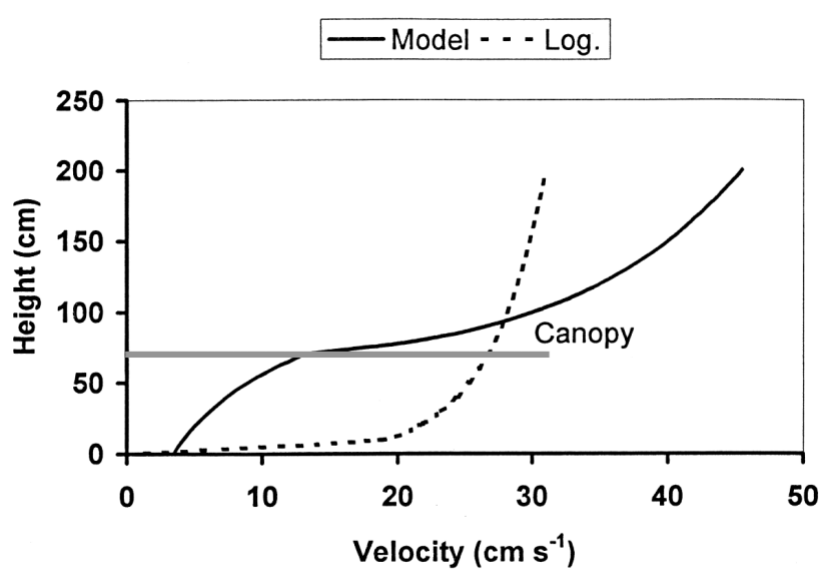

Fig. 7. Comparison of the vertical distribution of velocity from the logarithmic profile (Eq. 1) and model profiles (Eqs. 8 \& 9). As required by the above methodology, both profiles have the same integrated value

atmospherically deposited particles; and the distribution with a maximum at the bottom can represent suspended sediments (Gacia et al. 1999), ammonia, and larvae. Verduin et al. (1996) observed that pollen from the canopy may also have maximum values within the canopy and decrease in the overlying water. Studying the transport of a particular constituent would require more information (sources, sinks, rates, distributions, chemical/biological processes, etc.) and would exceed the scope of this paper, which only provides a tool for these studies.

Local fluxes ( $\mu \mathrm{g} \mathrm{cm}^{-2} \mathrm{~s}^{-1}$ ) were calculated for each vertical location $(z)$ by multiplying the concentration, $c(z)$, by the local velocity, $u(z)$. The total flux was calculated by integrating the local fluxes through the water depth, i.e.

$$
F=\int_{0}^{H} u(z) C(z) d z
$$

where $F$ is the total flux ( $\mu \mathrm{g} \mathrm{s}^{-1}$ ). As expected, the uniform distribution (with unit concentration) produced vertical distributions of flux with the same shape as the velocity profiles (Fig. 7) and integrated values that were almost equal (Table 5). The nonuniform distributions produced different patterns of transport, however. Fig. 9a and b show the results for maxima of concentration at the surface and at the bottom, respectively. Although the transport for both cases was reduced within the canopy and enhanced above it, the total transport was enhanced by $20 \%$ for a maximum at the surface and reduced by $29 \%$ for a maximum at the bottom (Table 5). Thus, the vertical dis-

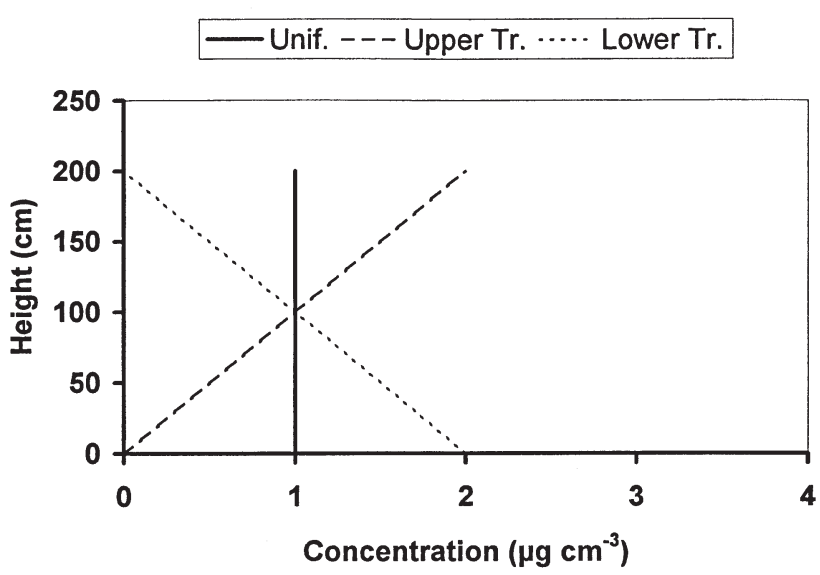

Fig. 8. Hypothetical vertical distributions of concentration ( $\mu \mathrm{g}$ $\mathrm{cm}^{-3}$ ) for conservative constituents representing uniform concentration (solid line), upper triangle with maximum concentration at the water surface (dashed line), and lower triangle with maximum concentration at the bottom (dotted line). The 3 distributions have the same integrated value $\left(200 \mu \mathrm{g} \mathrm{cm}^{-2}\right)$

tribution of a constituent determines whether the canopy will enhance or reduce its transport.

\section{SENSITIVITY ANALYSIS}

The sensitivity of the model was tested by changing its parameters and coefficients, with the hypothetical case from the section above being used as the reference. The basic parameters and coefficients are $u_{*}, z_{0}$, $H, h, W, C, C_{\mathrm{d}}, \lambda$, and $A_{\text {; }}$ all others depend on this set. Each parameter was tested separately. Transport was calculated by changing each parameter by $\pm 50 \%$ while keeping the others constant (Table 6). Sensitivities of transport in and above the canopy were also analyzed. Percent changes in transport were calculated as the changes divided by the baseline values. I also analyzed the actual change in transport and its fractional change relative to that of the parameter.

Assuming that values $<5 \%$ indicate negligible effects relative to the $50 \%$ changes in parameters,
Table 5. Total transport $\left(\mu \mathrm{g} \mathrm{s}^{-1}\right)$ for assumed vertical distributions of concentration (Fig. 8). The uniform vertical distribution of concentration has almost no effect on the total transport, but the upper and lower triangle distributions enhance and reduce it, respectively. The relative change $=$ (model value - logarithmic value) $\times 100 /$ logarithmic value

\begin{tabular}{|lcccc|}
\hline $\begin{array}{l}\text { Concentration } \\
\text { distribution }\end{array}$ & $\begin{array}{r}\text { Model } \\
\left(\mu \mathrm{g} \mathrm{s}^{-1}\right)\end{array}$ & $\begin{array}{c}\text { Logarithmic flow } \\
\left(\mu \mathrm{g} \mathrm{s}^{-1}\right)\end{array}$ & $\begin{array}{c}\text { Difference } \\
\left(\mu \mathrm{g} \mathrm{s}^{-1}\right)\end{array}$ & $\begin{array}{c}\text { Relative } \\
\text { change }(\%)\end{array}$ \\
\hline Uniform & 536.99 & 547.99 & -11.00 & -2.05 \\
Upper triangle & 729.38 & 609.98 & 119.39 & 19.57 \\
Lower triangle & 344.60 & 485.99 & -141.39 & -29.09 \\
\hline
\end{tabular}



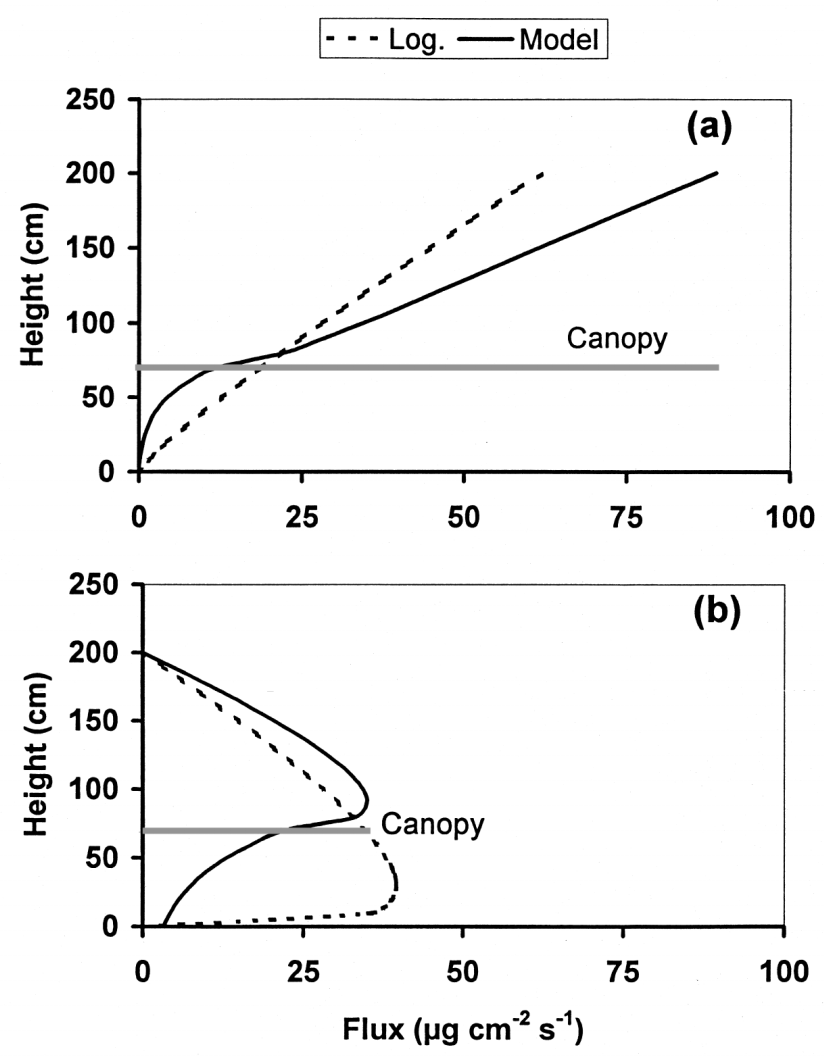

Fig. 9. Effect of canopy on vertical distribution of flux using the hypothetical linear distributions of concentration in Fig. 8: (a) flux for a distribution with maximum concentration at the surface, and (b) flux with maximum concentration at the bottom. Without the canopy effect, the respective vertical distributions for transport due to a logarithmic flow profile are shown (dashed lines) for comparison. Transport in both cases was reduced within the canopy and enhanced above it

transport in the canopy is found to be sensitive to all parameters. The results indicate that the model is least sensitive to changes in $w, A, c, c_{\mathrm{d}}$ and $\lambda$ and most sensitive to changes in $H, h, u_{*}$, and $z_{0}$. As indicated by the logarithmic velocity profile (Eq. 1), the latter parameters define the velocity profile and thus the transport in and above the canopy. The former parameters, however, relate more to flow within the canopy. They significantly affect transport within the canopy, but insignificantly affect transport above it and total transport. The smallest effect on canopy flow came from coefficient $c_{\mathrm{d}}$, which also affected total transport very little.

It is important to understand how the parameter and coefficients affect local and total transport. For example, the bottom roughness $\left(z_{0}\right)$ affects transport inversely because roughness retards flow. As expected, there is a direct 1-to-1 relationship between the friction velocity of the free stream $\left(u_{*}\right)$ and local and total transport. A similar relation exists between the water depth $(H)$ and transport above the canopy, but flow within the canopy decreases as $H$ increases $(h / H$ decreases) and vice versa. This shows that the ratio between $h$ and $H$ governs local transport, which is confirmed by the direct effect of $h$ (actually $h / H$ ) on canopy transport. Fonseca \& Fisher (1986) pointed to a positive relation between this ratio and canopy friction. The overall effect of $h$ on total transport, however, is an order of magnitude less than that of $H$ and $u_{*}$. The canopy drag is controlled by the width of the blades $(w)$ their density (as reflected by the horizontal area per blade, $A)$, and the drag coefficient $\left(C_{\mathrm{d}}\right)$. These parameters have a direct 1-to-1 effect on transport within the canopy (inverse relation for $w$ ).

The last 3 columns in Table 6 present the relation between the fractional change of transport $\left(\Delta F / F_{\text {refer- }}\right.$ ence) relative to the fractional change of the parameter $\left(\Delta P / P_{\text {reference }}\right)$, where $\Delta$ represents $(+/-)$ change in the parameter from the reference value. A value of 1 indicates that both fractions are the same, i.e. that a given fractional change (increase or decrease) in the parameter causes the same fractional change in transport. Negative values indicate an inverse relation (increases create decreases, and vice versa). Assuming that values $<0.05$ indicate a negligible effect relative to the 0.50 change in the parameter (Table 6 ), the model is least sensitive to $A, W, \lambda$, and $c_{\mathrm{d} i}$ moderately sensitive to $z_{0}, c_{1}$ and $h_{i}$ and most sensitive to $u_{*}$ and $H$. It is worth mentioning that, except for $u_{*}$, positive and negative fractional changes in all parameters produced unequal responses, which indicates that the system is inherently nonlinear (exponential within the canopy and logarithmic above it).

\section{DISCUSSION}

Although analogous analytical models exist for air flow in and above terrestrial canopies, this is one of the few attempts to model flow and transport in and above aquatic canopies. Kutija \& Hong (1996) used mixinglength theory to calculate shear stress above the vegetation and eddy viscosity within it. Their model includes stiffness of the plants and calculates the height of the canopy iteratively. It calculates eddy viscosity within the canopy from 4 calibration coefficients: Chezy's friction coefficient, drag coefficient, and 2 other numerical parameters. As hinted by the authors, the numerical procedure may be complex and slow. Part of that may be attributed to solving the unsteady-flow equation for steady flow, which requires starting from zero velocity and proceeding to the steady-state solution at each grid point and every new time increment. Verduin \& Backhaus (2000) presented a 3-dimensional numerical model in conjunction with 
Table 6. Sensitivity analysis of the basic model parameters and coefficients. When a parameter was changed all others were fixed at their reference value. The $\%$ change in transport = (transport with reference value changed by $\pm 50 \%$ - transport with reference value) $\times$ $100 /$ transport with reference value. The ratio of fractional changes of transport and model parameters $\left(\Delta F / F_{\text {reference }}\right) /\left(\Delta P / P_{\text {reference }}\right)$ with a value of 1 indicates that a unit increase (or decrease) in the rate of change in the parameter causes a similar rate of change in the transport. Negative values indicate an inverse relation, i.e. when the parameter increases the transport decreases, or vice versa

\begin{tabular}{|c|c|c|c|c|c|c|c|c|}
\hline \multirow[t]{2}{*}{ Parameter } & \multirow{2}{*}{$\begin{array}{l}\text { Reference } \\
\text { value } \\
\left(P_{\text {reference }}\right)\end{array}$} & \multirow{2}{*}{$\begin{array}{c}\text { \% change in } \\
\text { parameter }(100 \times \\
\left.P / P_{\text {reference }}\right)\end{array}$} & \multicolumn{3}{|c|}{$\%$ change in transport } & \multicolumn{3}{|c|}{ Fractional changes in transport } \\
\hline & & & $\begin{array}{l}\text { Within } \\
\text { canopy }\end{array}$ & $\begin{array}{l}\text { Above } \\
\text { canopy }\end{array}$ & $\begin{array}{c}\text { Total } \\
\text { change }\end{array}$ & $\begin{array}{l}\text { Within } \\
\text { canopy }\end{array}$ & $\begin{array}{l}\text { Above } \\
\text { canopy }\end{array}$ & $\begin{array}{c}\text { Total } \\
\text { change }\end{array}$ \\
\hline$u *\left(\mathrm{~cm} \mathrm{~s}^{-1}\right)$ & 1.63 & $\begin{array}{l}-50 \\
+50\end{array}$ & $\begin{array}{r}-50.0 \\
50.0\end{array}$ & $\begin{array}{r}-50.0 \\
50.0\end{array}$ & $\begin{array}{r}-50.0 \\
50.0\end{array}$ & $\begin{array}{l}1.00 \\
1.00\end{array}$ & $\begin{array}{l}1.00 \\
1.00\end{array}$ & $\begin{array}{l}1.00 \\
1.00\end{array}$ \\
\hline$z_{0}(\mathrm{~cm})$ & 0.1 & $\begin{array}{l}-50 \\
+50\end{array}$ & $\begin{array}{l}10.0 \\
-5.7\end{array}$ & $\begin{array}{l}10.4 \\
-6.1\end{array}$ & $\begin{array}{l}10.4 \\
-6.0\end{array}$ & $\begin{array}{l}-0.20 \\
-0.11\end{array}$ & $\begin{array}{l}-0.21 \\
-0.12\end{array}$ & $\begin{array}{l}-0.21 \\
-0.12\end{array}$ \\
\hline$w(\mathrm{~cm})$ & 0.4 & $\begin{array}{l}-50 \\
+50\end{array}$ & $\begin{array}{r}28.2 \\
-14.2\end{array}$ & $\begin{array}{r}-4.2 \\
2.4\end{array}$ & $\begin{array}{r}-0.7 \\
0.6\end{array}$ & $\begin{array}{l}-0.56 \\
-0.28\end{array}$ & $\begin{array}{l}0.09 \\
0.05\end{array}$ & $\begin{array}{l}0.01 \\
0.01\end{array}$ \\
\hline$A\left(\mathrm{~cm}^{2}\right)$ & 5.71 & $\begin{array}{l}-50 \\
+50\end{array}$ & $\begin{array}{r}-23.1 \\
16.0\end{array}$ & $\begin{array}{r}4.0 \\
-2.5\end{array}$ & $\begin{array}{r}1.0 \\
-0.5\end{array}$ & $\begin{array}{l}0.46 \\
0.32\end{array}$ & $\begin{array}{l}-0.08 \\
-0.05\end{array}$ & $\begin{array}{l}-0.02 \\
-0.01\end{array}$ \\
\hline C & 1.2 & $\begin{array}{l}-50 \\
+50\end{array}$ & $\begin{array}{r}-36.6 \\
12.8\end{array}$ & $\begin{array}{r}-4.6 \\
0.8\end{array}$ & $\begin{array}{r}-8.1 \\
2.1\end{array}$ & $\begin{array}{l}0.73 \\
0.26\end{array}$ & $\begin{array}{l}0.09 \\
0.02\end{array}$ & $\begin{array}{l}0.16 \\
0.04\end{array}$ \\
\hline$c_{\mathrm{d}}$ & 0.7 & $\begin{array}{l}-50 \\
+50\end{array}$ & $\begin{array}{r}9.3 \\
-5.8\end{array}$ & $\begin{array}{r}-1.4 \\
0.9\end{array}$ & $\begin{array}{r}-0.2 \\
0.1\end{array}$ & $\begin{array}{l}-0.19 \\
-0.12\end{array}$ & $\begin{array}{l}0.03 \\
0.02\end{array}$ & $\begin{array}{l}0.004 \\
0.003\end{array}$ \\
\hline$\lambda(\mathrm{cm})$ & 67.25 & $\begin{array}{l}-50 \\
+50\end{array}$ & $\begin{array}{r}-20.2 \\
10.8\end{array}$ & $\begin{array}{r}3.1 \\
-1.6\end{array}$ & $\begin{array}{r}0.5 \\
-0.2\end{array}$ & $\begin{array}{l}0.40 \\
0.22\end{array}$ & $\begin{array}{l}-0.06 \\
-0.03\end{array}$ & $\begin{array}{l}-0.01 \\
-0.01\end{array}$ \\
\hline$h(\mathrm{~cm})$ & 70 & $\begin{array}{l}-50 \\
+50\end{array}$ & $\begin{array}{r}-40.0 \\
88.5\end{array}$ & $\begin{array}{r}12.4 \\
-17.2\end{array}$ & $\begin{array}{r}6.7 \\
-5.7\end{array}$ & $\begin{array}{l}0.80 \\
1.77\end{array}$ & $\begin{array}{l}-0.25 \\
-0.34\end{array}$ & $\begin{array}{l}-0.13 \\
-0.11\end{array}$ \\
\hline$H(\mathrm{~cm})$ & 200 & $\begin{array}{l}-50 \\
+50\end{array}$ & $\begin{array}{r}43.1 \\
-13.0\end{array}$ & $\begin{array}{r}-76.7 \\
76.9\end{array}$ & $\begin{array}{r}-63.7 \\
67.1\end{array}$ & $\begin{array}{l}-0.86 \\
-0.26\end{array}$ & $\begin{array}{l}1.53 \\
1.54\end{array}$ & $\begin{array}{l}1.27 \\
1.34\end{array}$ \\
\hline
\end{tabular}

an unpublished canopy model in order to describe the interaction between flow and Amphibolis antarctica. In addition to predicting velocity profiles, kinetic energy, and drag in and above the canopy, it predicted plant flapping due to wave action.

Behavior similar to our model (logarithmic and exponential profiles of velocity; reduced flow in the canopy and enhanced flow above it) has indeed been observed for submerged eelgrass (Fonseca et al. 1982, 1983, Fonseca \& Kenworthy 1987, Gambi et al. 1990, Neph \& Vivoni 2000). There are also experimental indications that different logarithmic velocity profiles exist in and above eelgrass canopies, with an inflection point at the top of the canopy (Fonseca 1990). Flow rate within submerged Callitriche stagnalis has been found to be reduced by 60 to $90 \%$, with the maximum reduction at the edge of the canopy (Madsen \& Warncke 1983).

Validating the present model with field data requires information about the plants (i.e. width and density of blades), bottom roughness, depth, and canopy height, as well as estimates for the drag coefficient $\left(c_{\mathrm{d}}\right)$ and the proportionality coefficient $c$. The calibrated values for these coefficients provided reasonable preliminary confirmations of the flow fields observed in the laboratory studies of Gambi et al. (1990). The different plant morphologies found in our field data, however, required that $C$ be changed. More rigorous analysis may be needed to define these coefficients for other morphologies, even though the model is not particularly sensitive to them.

The most direct application of the model is in the analysis of the transport of contaminants and suspended particulates in eelgrass canopies when the upstream vertical distributions of constituents of interest are known. The model shows that the canopy only negligibly affects total transport of constituents with uniform vertical concentrations, but increases and decreases total transport for constituents with maxima at the top and the bottom, respectively. This alteration of transport may have pronounced effects on exchange processes and residence times in enclosed and semienclosed embayments (Rybicki et al. 1997). The model provides the physical parameter (flow profile) that most directly affects the transport of conservative constituents. Nonconservative constituents (such as nutrients) cannot be modeled until their kinetics, sources, and sinks are known, however.

The model presented here holds only for steady-state conditions. In fact, 2 of its variables ( $H$ and $u_{*}$ ) vary with tidal phase, as noted above. For dealing with individual 
tidal phases (nonsteady state), values for these variables should be estimated for each phase from field measurements, numerical models, or analytical approximations. The total transport during a tidal cycle would then be calculated from the following integration:

$$
F=\int_{0}^{T} \int_{0}^{H(t)} u(z, t) C(z, t) d z d t
$$

where $T$ is the tidal period. Assuming that the logarithmic flow field varies sinusoidally, the friction velocity, $u_{*}$, can be represented by:

$$
u_{*}=u_{* \max } \cos (\omega t+\varphi)
$$

where $u_{* \max }$ is the friction velocity during maximum tidal currents, $\pi$ is the tidal frequency $(2 \tau / T)$, and $\varphi$ is a phase shift. If $c(z, t)$ is known, the total tidal transport $(F)$ can be obtained by first substituting $u_{*}$ into Eqs. (1) \& (12), which indirectly affect Eqs. (8) \& (9), and then applying Eq. (18). Of course, a symmetric tide with time-invariant concentration profiles will produce no net transport over a cycle, but an asymmetric tide or time-varying profile will produce a net transport in the direction of the tidal excursion.

The limitations of the present model are not serious and do not outweigh its benefits. (1) The fact that the model is valid only for submerged canopies where $H / h=2$ does not significantly limit its use because this case is more common for eelgrass than depth limitation $(H<2 h)$, and the emergent case does not apply to eelgrass. (2) The spatial variability near the leading edge of the canopy and the dynamic coupling between the flow field and eelgrass will be dealt with separately (Abdelrhman unpubl.). This coupling may allow changing tidal velocities to change the height of the canopy $(h)$ because high velocities bend the blades more (Fonseca \& Kenworthy 1987). There are also indications that friction from a canopy depends on the canopy's height relative to the water depth (Fonseca \& Fisher 1986). This effect was not evident in our field data, however, because during 2 periods when velocities changed between high and slack values, the canopy was always 53 to $68 \mathrm{~cm}$ high (Table 4) and the plants did not lie flat on the bed (perhaps because they were too thick). A similar effect was noticed in Gambi's data (Table 3), which showed that the canopy's height decreased only slightly, from 10.5 to $9.0 \mathrm{~cm}$, as the current increased from 5 to $20 \mathrm{~cm} \mathrm{~s}^{-1}$. (3) The fact that estimated velocities do not reach zero at the sediment (even though the model adequately resolves the velocity profile within most of the rest of the canopy) does not matter much for transport because these overestimated velocities increase the estimated total transport only negligibly. (The velocities are small and act only in a thin layer.) This deficiency, however, prevents the model from being applied to matters related to the effect of flow on benthic organisms, erosion of bed material, and dispersion of pore-water constituents to the overlying water column. Although some empirical models force the velocity profile to zero at the bed (e.g. Cowan 1968), I am not aware of any theoretically justifiable model that deals with the near-bed boundary layer within plant canopies. Laboratory observations with emergent plants (Nepf et al. 1997b) have indicated that this near-bed layer is only 0.1 times the water depth (1 $\mathrm{cm}$ in their case). Thus the discussion below applies to the whole canopy minus this layer. Even a layer this thin could still be important.

The present model quantitatively resolves the vertical distribution of flow inside canopies and estimates shear stresses there, which are equivalent to the levels of turbulence and fluid drag (see Appendix 1). These physical factors directly affect ecological processes related to the plants and their associated organisms. The advantage of this approach is illustrated by Fig. 10, which presents the vertical distributions of shear stresses (Eq. A11) for the 3 levels of velocities used by Gambi et al. (1990). The distributions show that turbulence is highest near the canopy-water interface and decreases downward, in agreement with Gambi et al.'s direct measurements. These distributions can also aid in quantitatively analyzing the effects on ecological processes within the canopy as a whole and at specific heights within it. For example, increasing the shear velocities in a microcosm was found to reduce the diffusive layer on the blades of Thalassia testudinum and Cymodocea nodosa and thereby to increase the uptake of nutrients and promote photosynthesis (Koch 1994). Similar relationships between high velocity (and turbulence) in freshwater

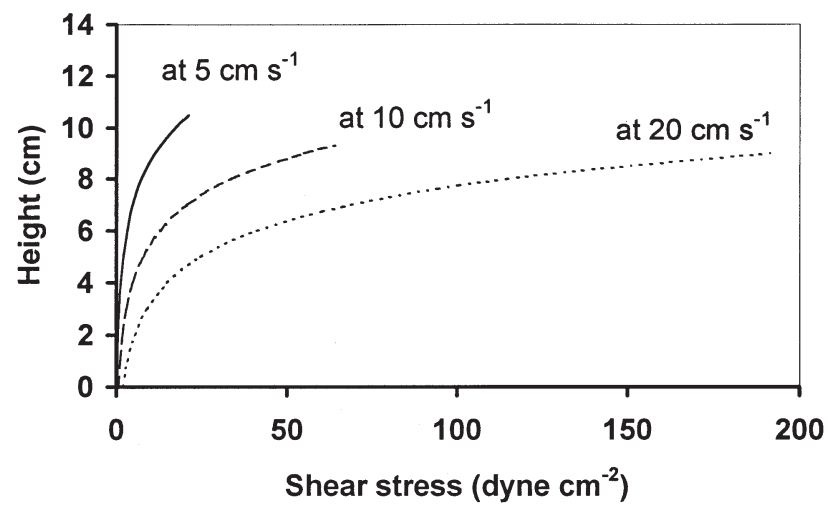

Fig. 10. Example of vertical distributions of horizontal shear stress (Eq. A11; see Appendix 1) calculated from the modeled canopy flow (Fig. 2) by using data from Gambi et al. (1990) for plant density of 1000 shoots $\mathrm{m}^{-2}\left(3900\right.$ blades $\left.^{-2}\right)$ at velocities of 5,10 , and $20 \mathrm{~cm} \mathrm{~s}^{-1}$. Shear stresses increase throughout the canopy as current speeds increase from 5 to $20 \mathrm{~cm} \mathrm{~s}^{-1}$. Maximum shear stresses exist near the top of the canopy, at the interface with the water, and decrease downward into the canopy 
canopies and photosynthesis there were also emphasized by Sand-Jensen \& Mebus (1996). Also, Dennison \& Alberte (1982) indicated that self-shading reduces the vertical distribution of light intensity in the canopy to the extent that the base of the eelgrass may receive only $10 \%$ of the light intensity at the tips. The present model now allows these effects on photosynthesis, stemming from both the vertical distributions of shear stress and light intensity, to be studied simultaneously and quantitatively within a canopy.

Another potential application relates to the settling of larvae and particulates, which is strongly affected by turbulent flow near the bottom (Eckman 1983). The numerical models of Gross et al. (1992) and Eckman et al. (1994) predicted the settling of larvae within turbulent boundary layers over bare bottoms, but did not include flow within canopies. They emphasized the importance of the interactions between larval fall velocity and velocity gradient (or turbulence), the latter of which also controls the probability of attachment during a tidal cycle (Gross et al. 1992). Fonseca \& Fisher (1986) studied how canopy friction for 4 species of seagrass (Thalassia testudinum, Halodule wrightii, Zostera marina, and Syringodium filiforme) affected sedimentation and erosion at different densities and velocities. Although they indicated that a logarithmic profile existed above these canopies, as predicted by this model, they did not deal with flow within the canopies. Thus, the model presented here may be useful in further studying the transport of larvae, sediment, and pollen within the canopy itself during the various tidal phases.

The model can also help us understand the ways that hydrodynamics affects recruitment, growth, and survival of organisms inhabiting eelgrass meadows (e.g. bryozoans, serpulids, hydrozoans, spionid polychaetes, tanaids, caprellid amphipods, bay scallop, and jingle). These phenomena were described by Eckman (1987) for the bay scallop Argopecten irradians (L.) and the common jingle Anomia simplex (D'Orbigny). He showed qualitatively that the main governing factor is the density of eelgrass shoots (i.e. biomass), because it controls the overall flow and flux of water within the canopy (see also Sand-Jensen \& Mebus [1996] for freshwater canopies). I hypothesize, however, that these ecological processes vary directly with vertical distributions of both current speed and shear stress (e.g. Fig. 10), rather than with plant density, because the upper parts of the canopy, with their higher current and shear, differ from the lower parts with lesser currents and shear, even for the same plant density and water flow. Moreover, we know that current speeds and shear stresses do change during tidal cycles, even when plant densities remain the same. In the same direction, Vogel (1994, p. 183-186) indicated that some larvae prefer lower shear for better attachment and survival, while others choose higher shear for rapid growth and adult fecundity, and he complained that the existing literature treated larval recruitment as a function of flow speed rather than of the real controlling mechanisms, velocity gradient and shear. The present model defines the quantitative relationships between plant density and the speed and shear of current, and thus it provides a quantitative means to better study recruitment of organisms on eelgrass blades at various heights within the canopy and during the various tidal phases.

\section{SUMMARY}

While flow modifications by eelgrass and SAV canopies have been the subject of numerous field and laboratory studies, very few models have been developed for tackling flow and transport in and above eelgrass in the way that this model does. The advantage of this model is its simplicity and applicability as a stand-alone tool for quickly calculating velocity profiles, shear, and transport, or as a module in moresophisticated circulation models such as that of Verduin \& Backhaus (2000). The ability to quantitatively define profiles of flow and shear in and above eelgrass opens an avenue for evaluating numerous related ecological processes in beds with various densities and morphologies. A logical extension of this model would be to relate the vertical distribution of shear within the canopy to turbulence, shear on blade surfaces, and ultimately to nutrient uptake, as well as to the other biological and ecological effects discussed above. Nevertheless, as indicated by Gross et al. (1992), the appropriate way to begin studying the effects of physics on biology is to elucidate the relevant biology, as for example in the attempts of Eckman et al. (1990) to quantitatively link the duration of attachment to the drag forces working toward detachment.

Acknowledgements. The author would like to thank the reviewers of this manuscript, including Drs. Dan Campbell, Glen Thursby, and Cathleen Wigand (USEPA-AED), and 2 anonymous reviewers for their technical reviews, insights, and constructive comments. Special thanks are due to Dr. Kenneth Rahn (CSC) for both technical and editorial comments on the manuscript. Although the research described in this article has been funded by the US Environmental Protection Agency, it has not been subject to Agency-level review and therefore does not necessarily reflect the views of the Agency, nor does the mention of trade names or commercial products endorse or recommend them. This manuscript is contribution no. AED-98-2061 of USEPA Office Research and Development, National Health and Environmental Effects Research Laboratory, Atlantic Ecology Division. 
Appendix 1. Derivation of equations for flow and shear within the canopy

The basic equation for airflow within a dense canopy was derived from diffusion theory (Raupach \& Thom 1981). For a homogeneous canopy subject to steady flow, the equation for transport of horizontal momentum in the direction of flow reduced after temporal and spatial averaging to

$$
\frac{\partial<\overline{u^{\prime} w^{\prime}}>}{\partial z}=F_{\mathrm{d}}
$$

where $u^{\prime}$ and $w^{\prime}$ are turbulent fluctuations from their timeaveraged values, and $F_{\mathrm{d}}$ is the total form drag. The overbar represents a temporal average, and $<>$ represents horizontal spatial average of that time average over an area with dimensions large enough to eliminate variations from individual roughness elements. Eq. (A1) assumes that the flow is unconfined, with negligible longitudinal pressure gradient, and that form drag dominates viscous effects in the canopy. The vertical flux of momentum equals the surface stress (Businger 1975), i.e.

$$
\frac{\tau_{z}}{\rho}=-<\overline{u^{\prime} w^{\prime}}>
$$

where $\tau_{z}$ is the shear stress at $z$ and $\rho$ is the density of water. With parametrization analogous to form drag on a single element to represent drag within the canopy, Eq. (A1) becomes

$$
\frac{\partial \tau}{\partial z}=\rho c_{\mathrm{d}} a u_{z}^{2}
$$

where $c_{\mathrm{d}}$ is a velocity-dependent drag coefficient on a single blade and $a$ is the frontal area of individual elements per unit volume of canopy (Raupach \& Thom 1981). For a uniform canopy, $a$ is constant. The shear stress is expressed in terms of the mean velocity by

$$
\tau_{z}=\rho K_{z} \frac{\partial u_{z}}{\partial z}
$$

where $K_{z}$ is the coefficient of eddy viscosity within the canopy. Substituting from Eq. (A4) into Eq. (A3) gives

$$
\frac{\partial K_{z}}{\partial z} \frac{\partial u_{z}}{\partial z}+K_{z} \frac{\partial^{2} u_{z}}{\partial z^{2}}=c_{\mathrm{d}} a u_{z}^{2}
$$

$K_{z}$ is defined by mixing-length theory as

$$
K_{z}=\lambda^{2} \frac{\partial u_{z}}{\partial z}
$$

where $\lambda$ is the mixing length of the turbulent flow within the canopy (Watanab \& Kundo 1990). When $\lambda$ is constant, Eq. (A5) reduces to

$$
\left(\frac{\partial^{2} u_{z}}{\partial z^{2}}\right)\left(\frac{\partial u_{z}}{\partial z}\right)=\left(\frac{c_{\mathrm{d}} a}{2 \lambda^{2}}\right) u_{z}^{2}
$$

For the special case when $a$ and $c_{\mathrm{d}}$ are constants, the most famous solution of Eq. (A7) is

$$
u_{z}=u_{h} \exp \left[\alpha\left(\frac{z}{h}-1\right)\right]
$$

where $u_{h}$ is the free-stream velocity at the top of the canopy $(z=h)$ and $\alpha$ is an attenuation coefficient given by

$$
\alpha=h\left[\frac{C_{\mathrm{d}} \mathrm{a}}{2 \lambda^{2}}\right]^{\frac{1}{3}}
$$

The vertical distribution of shear stress within the canopy can be calculated by integrating Eq. (A3). The result is

$$
\tau_{z}=\int_{0}^{z} \rho c_{\mathrm{d}} a u_{z}^{2} d z
$$

Substituting $u_{z}$ from Eq. (A8) gives

$$
\tau_{z}=\frac{\rho c_{\mathrm{d}} a u_{h}^{2} h}{2 \alpha}\left(\exp \left[2 \alpha\left(\frac{z}{h}-1\right)\right]\right)
$$

\section{LITERATURE CITED}

Ackerman JD (1986) Mechanistic implications for pollination in the marine angiosperm Zostera marina. Aquat Bot 24: $343-353$

Ackerman JD, Okubo A (1993) Reduced mixing in a marine macrophyte canopy. Funct Ecol 7:305-309

Anderson SM, Charters AC (1982) A fluid dynamic study of seawater flow through Gelidium nudifrons. Limnol Oceanogr 27(3):399-412

Bilhco RG, Partheniades E (1971) Turbulence characteristics in free surface flows over smooth and rough boundaries. J Hydraulic Res 9:43-69

BioSonics (1998) Guide to using DT Series hard and software. Manual Version V. 2.1. BioSonics, Seattle, WA

Businger JA (1975) Aerodynamics of vegetated surfaces. In: Devries DA, Afgan NH (eds) Heat and mass transfer in the biosphere, Part I. Transfer processes in the plant environment. Scripta, Washington, DC

Businger JA, Wyngaard JC, Izumi Y, Bradely EF (1971) Flux profile relationships in the atmospheric surface layer. J Atmos Sci 28:181-189

Cionco RM (1965) A mathematical model for air flow in a vegetative canopy. J Appl Meteorol 4:517-522

Cionco RM (1983) On the coupling of canopy flow to ambient flow for a variety of vegetation types and densities. Boundary-Layer Meteorol 26:325-335
Cowan IR (1968) Mass, heat, and momentum exchange between stands of plants and their atmospheric environment. Q J R Meteorol Soc 94:318-332

Dennison WC, Alberte RS (1982) Photosynthetic response of Zostra marina L. (Eelgrass) to in situ manipulation of light intensity. Oceanologia (Berl) 55:137-144

Dennison WC, Orth RI, Moore KA, Stevenson JC, Carter V, Kollar S, Bergstrom PW, Batiuk RA (1993) Assessing water quality with submerged aquatic vegetation. BioScience 43:86-94

Eckman JE (1983) Hydrodynamic process affecting benthic recruitment. Limnol Oceanogr 28(2):241-257

Eckman JE (1987) The role of hydrodynamic in recruitment, growth, and survival of Argopecten irradians (L.) And Anomia simplex (D'Orbigny) within eelgrass meadows. J Exp Mar Biol Ecol 106:165-191

Eckman JE, Savidge WB, Gross TF (1990) Relation between duration of cyprid attachment and drag forces associated with detachment of Balanus amphitrite cyprids. Mar Biol 107:111-118

Eckman JE, Werner FE, Gross TF (1994) Modeling some effects of behavior on larval settlement in a turbulent boundary layer. Deep-Sea Res 41(1):185-208

Fish and Wild Life (1984) The ecology of eelgrass meadows of the Atlantic coast: a community profile. Report No. FWL/OBS-84/02, US Department of the Interior, Fish and Wild Life Service, Washington, DC 
Fonseca MS (1990) Physical measurements. In: Phillip RC, McRoy CP (eds) Seagrass research methods. UNESCO, Paris

Fonseca MS, Fisher JS (1986) A comparison of canopy friction and sediment movement between four species of seagrass with reference to their ecology and restoration. Mar Ecol Prog Ser 29:15-22

Fonseca MS, Kenworthy WJ (1987) Effect of current on photosynthesis and distribution of seagrasses. J Aquat Bot 27:59-78

Fonseca MS, Fisher JS, Zieman JC, Thayer GW (1982) Influence of the seagrass, Zostera marina L., on Current Flow. Estuar Coast Shelf Sci 15:351-364

Fonseca MS, Zieman JC, Thayer GW, Fisher JS (1983) The role of current velocity in structuring eelgrass (Zostera marina) meadows. Estuar Coast Shelf Sci 17:367-380

Gacia E, Granata TC, Duarte CM (1999) An approach to measurement of particle flux and sediment retention within seagrass (Posidonia oceanica) meadows. Aquat Bot 65: 255-268

Gambi MC, Nowell ARM, Jumars PA (1990) Flume observations of flow dynamics in Zostera marina (eelgrass) beds. Mar Ecol Prog Ser 61:159-169

Ghisalberti M, Nepf HM (2002) Mixing layers and coherent structures in vegetated aquatic flows. J Geophys Res 107(C2):1-11

Granata TC, Serra T, Colomer J, Casamitijana X, Duarte CM, Gacia E (2001) Flow and particle distribution in a nearshore seagrass meadow before and after a storm. Mar Ecol Prog Ser 218:95-106

Grant WD, Williams AJ III, Glenn SM (1984) Bottom stress estimates and their prediction on the northern California continental shelf during COD-1: the importance of wavecurrent interaction. J Phys Oceanogr 14:506-527

Grizzle RE, Short FT, Newell CR, Hoven H, Kindblom L (1996) Hydrodynamically induced synchronous waving of seagrass: 'monami' and its possible effects on larval mussel settlement. J Exp Mar Biol Ecol 206:165-177

Gross TF, Werner FE, Eckman JE (1992) Numerical modeling of larval settlement in turbulent bottom boundary layers. J Mar Res 50:611-642

Hartog G, Shaw RH (1975) Aerodynamics of vegitated surfaces. In: Devries DA, Afgan NH (eds) Heat and mass transfer in the biosphere, Part I. Transfer processes in plant environment, Chap 19. John Wiley, New York

Jackson PS (1981) On the displacement height in the logarithmic velocity profile. J Fluid Mech 111:15-25

Kenworthy WJ, Fonseca MS (1980) Development of a transplanted seagrass (Zostera marina L.) Meadow in Back Sound, Carteret County, North Carolina. Contribution Number 80-55B. In: Cole DP (ed) Proceedings of the 7th Annual Conference on the Restoration and Creation of Wetlands. National Marine Fisheries Service, Southeast Fisheries Center, Beaufort Laboratory, Tampa, FL, p 175-190

Kenworthy WJ, Fonseca MS, Hornziak J, Thayer GW (1980) Development of a transplanted seagrass (Zostera marina L.) meadow in Back Sound, Carteret County, North Carolina. In: Cole DP (ed) Proceedings of the 7th Annual Conference on the Restoration and Creation of Wetlands. Hillsborough Community College, Tampa FL, p 175-193

Koch EW (1994) Hydrodynamic, diffusion-boundary layers and photosynthesis of seagrass Thalassia testudinum and Cymodocea nodosa. Mar Biol 118:767-776

Koch EW (1996) Hydrodynamics of a shallow Thalassia testudinum bed in Florida USA. In: Kuo J, Phillips RC, Walker DI, Kirkman H (eds) Seagrass biology. Proceedings of an
International Workshop, Rottnest Island, Western Australia, 25-29 January, p 105-110

Koch EW (1999) Sediment resuspension in a shallow Thalassia testudinum banks ex Konig bed. Aquat Bot 65:269-280

Koehl MAR, Alberte RS (1988) Flow, flapping, and photosynthesis of Nereocystis luetkeana: a functional comparison of undulate and flat blade morphologies. Mar Biol 99:435-444

Kutija V, Hong HTM (1996) A numerical model for assessing the additional resistance to flow introduced by flexible vegetation. J Hydraulic Res 34:99-114

Legg B, Monteith J (1975) Heat and mass transfer within plant canopies. In: Devries DA, Afgan NH (eds) Heat and mass transfer in the biosphere, Part I. Transfer processes in the plant environment. Scripta, Washington, DC

Leonard LA, Luther ME (1995) Flow hydrodynamics in tidal marsh canopies. Limnol Oceanogr 40(8):1474-1484

Madsen TV, Warncke E (1983) Velocity of currents around and within submerged aquatic vegetation. Arch Hydrobiol 97(3):389-394

Nepf HM (1999) Drag, turbulence, and diffusion in flow through emergent vegetation. Water Resour Res 35(2):479-489

Nepf HM, Vivoni ER (2000) Flow structure in depth-limited vegetated flow. J Geophys Res 105:28547-28557

Nepf HM, Mugnier CG, Zavistoski RA (1997a) The effects of vegetation on longitudinal dispersion. Estuar Coast Shelf Sci 44:675-684

Nepf HM, Sullivan JA, Zavistoski RA (1997b) A model for diffusion within emergent vegetation. Limnol Oceanogr 42(8): 1735-1745

Niklas KJ (1992) Plant biomechanics: an engineering approach to plant form and function. University of Chicago Press, Chicago

Oliver HR (1971) Wind profiles in and above a forest canopy. Q J R Meteorol Soc 97:548-553

Plate EJ, Quraishi AA (1964) Modeling of velocity distribution inside and above tall crops. J Appl Meteorol 4:400-408

Pruitt WD, Morgan DL, Laurence FJ (1973) Momentum and mass transfers in the surface boundary layer. J Met Soc 99:370-386

Raupach MR, Shaw RH (1982) Averaging procedures for flow within vegetation canopies. Boundary-Layer Meteorol 22: 79-90

Raupach MR, Thom AS (1981) Turbulence in and above plant canopies. Annu Rev Fluid Mech 13:97-129

Raupach MR, Finnigan JJ, Brunt Y (1996) Coherent eddies and turbulence in vegetation canopies: the mixing layer analogy. Boundary-Layer Meteorol 78:351-382

Rybicki NB, Jenter HL, Carter V, Baltzer RA, Turtora M (1997) Observations of tidal flux between a submersed aquatic plant and the adjacent channel in Potomac River near Washington DC. Limnol Oceanogr 42(2):307-317

Sabol BM, McCarthy E, Rocha K (1997) Hydroacoustic basis for detection and characterization of eelgrass (Zostera marina). In: Proceedings of the Fourth Conference on Remote Sensing for Marine and Coastal Environments, Orlando, Florida, 17-19 March 1997. Environmental Research Institute of Michigan, Ann Arbor, MI, p I-679- I-693

Sabol BM, Melton RE Jr, Chamberlain R, Doering P, Haunert K (2002) Evaluation of a digital echo sounder system for detection of submersed aquatic vegetation. Estuaries 25(1):133-141

Sand-Jensen K, Mebus JR (1996) Fine-scale patterns of water velocity within macrophyte patches in streams. Oikos 76: $169-180$

Schutten J, Davey AJ (2000) Predicting the hydraulic forces on submerged macrophytes from current velocity, biomass and morphology. Oecologia 123:445-452 
Seginer I, Mulhearn PJ, Bradley EF, Finnigan JJ (1976) Turbulent flow in a model plant canopy. Boundary-Layer Meteorol 10:423-453

Short FT, Burdick DM (1996) Quantifying eelgrass habitat loss in relation to housing development and nitrogen loading in Waquoit Bay, Massachusetts. Estuaries 19(3): 730-739

Short FT, Short CA (1984) The seagrass filter: purification of coastal waters. In: Kennedy VS (ed) The estuary as a filter. Academic Press, London, p 395-413

Solana-Arellano E, Echavarria-Heras HA, Ibarra-Obando SE (1997) Leaf-size dynamics for Zostera marina L. in San Quintin Bay, Mexico: a theoretical study. J Estuar Coast Shelf Sci 44:351-359

Sternberg RW (1968) Friction factors in tidal channels with differing bed roughness. Mar Geol 6:243-260

Sverdrup HU, Johnson MW, Fleming RH (1942) The oceans, their physics, chemistry, and general biology. PrenticeHall, Englewood Cliffs, NJ

Verduin JJ, Backhaus JO (2000) Dynamics of plant-flow inter-

Editorial responsibility: Kenneth Heck (Contributing Editor), Dauphin Island, Alabama, USA actions for the seagrass Amphibolis antarctica: field observations and model simulations. Estuar Coast Shelf Sci 50:185-204

Verduin JJ, Walker DI, Kuo J (1996) In situ submarine pollination in seagrass Amphibolis antarctica: research notes. Mar Ecol Prog Ser 133:307-309

Vogel S (1994) Life in moving fluids, the physical biology of flow, 2nd edn. Princeton University Press, Princeton, NJ

Ward LG, Kemp WM, Boynton WR (1984) The influence of waves and seagrass communities on suspended particulates in an estuarine embayment. J Mar Geol 59:85-103

Watanab T, Kondo J (1990) The influence of canopy structure and density upon the mixing length within and above vegetation. Meteorol Soc Jpn 68:227-235

Worcester SE (1995) Effects of eelgrass beds on advection and turbulent mixing in low current and low shoot density environments. Mar Ecol Prog Ser 126:223-232

Wright JL, Brown KW (1967) Comparison of momentum and energy balance methods of computing vertical transfer within a crop. Agron J 59:427-432

Submitted: November 16, 2001; Accepted: October 7, 2002 Proofs received from author(s): January 20, 2003 